\title{
Energetic Optimization and Exergetic Performance Investigation of an Ejector System Using HCFO-1233zd(E) as a Refrigerant
}

\author{
Aggrey Mwesigye, Amir Kiamari, and Seth B. Dworkin* \\ Department of Mechanical and Industrial Engineering \\ Ryerson University \\ 350 Victoria Street, Toronto, Canada \\ (*Corresponding author: seth.dworkin@,ryerson.ca)
}

\begin{abstract}
In this study, the performance of an ejector refrigeration system using HCFO-1233zd(E) as the working fluid is investigated and presented. A novel improved modeling approach that considers ejector loss coefficients as functions of the ejector pressure lift and area ratio has been used. The resulting mathematical model developed using the first and second laws of thermodynamics and gas dynamics is solved using Engineering Equation Solver. Different ejector geometries with area ratios of $6.44,7.04,7.51,7.73,8.28,8.62,9.13,9.41$ and 10.64 were used in this study. The evaporator temperatures were between $0{ }^{\circ} \mathrm{C}$ and $16^{\circ} \mathrm{C}$, the generator temperatures were between $75^{\circ} \mathrm{C}$ and $120^{\circ} \mathrm{C}$ and the condensing temperatures varied between $20^{\circ} \mathrm{C}$ and $40^{\circ} \mathrm{C}$. For the range of parameters used, the optimal coefficient of performance (COP) is in the range 0.11 and 0.88 for evaporator temperatures between $4{ }^{\circ} \mathrm{C}$ and $16{ }^{\circ} \mathrm{C}$. At the optimal working conditions, the $\mathrm{COP}$ improves with higher area ratios, lower condensing temperatures and requires increased generator temperatures. In the critical mode of operation, both the energetic and exegetic performance of the ejector are shown to decline as generator temperatures increase, evaporator temperatures reduce and as the area ratios decrease. Thermodynamic investigation using the exergy analysis method indicates that most of the exergetic losses come from the ejector (46-56\%) followed by the condenser (18-29\%), the generator (21-26\%), the evaporator (0.8-3\%), and the throttle valve (1$1.6 \%$ ), with the pump having a very small contribution. Moreover, correlations for the optimal generator and optimal COP were derived and presented.
\end{abstract}

Keywords: Coefficient of performance, Critical mode, Ejector refrigeration system, Ejector loss coefficients, Exergetic performance, Hydroflouroolefins

\section{Nomenclature}

$$
\begin{array}{ll}
A & \text { Area, } \mathrm{m}^{2} \\
A_{r} & \text { Ratio of mixing section cross-section area to the ejector throat cross-section area, } \\
& A_{3} / A_{t}
\end{array}
$$




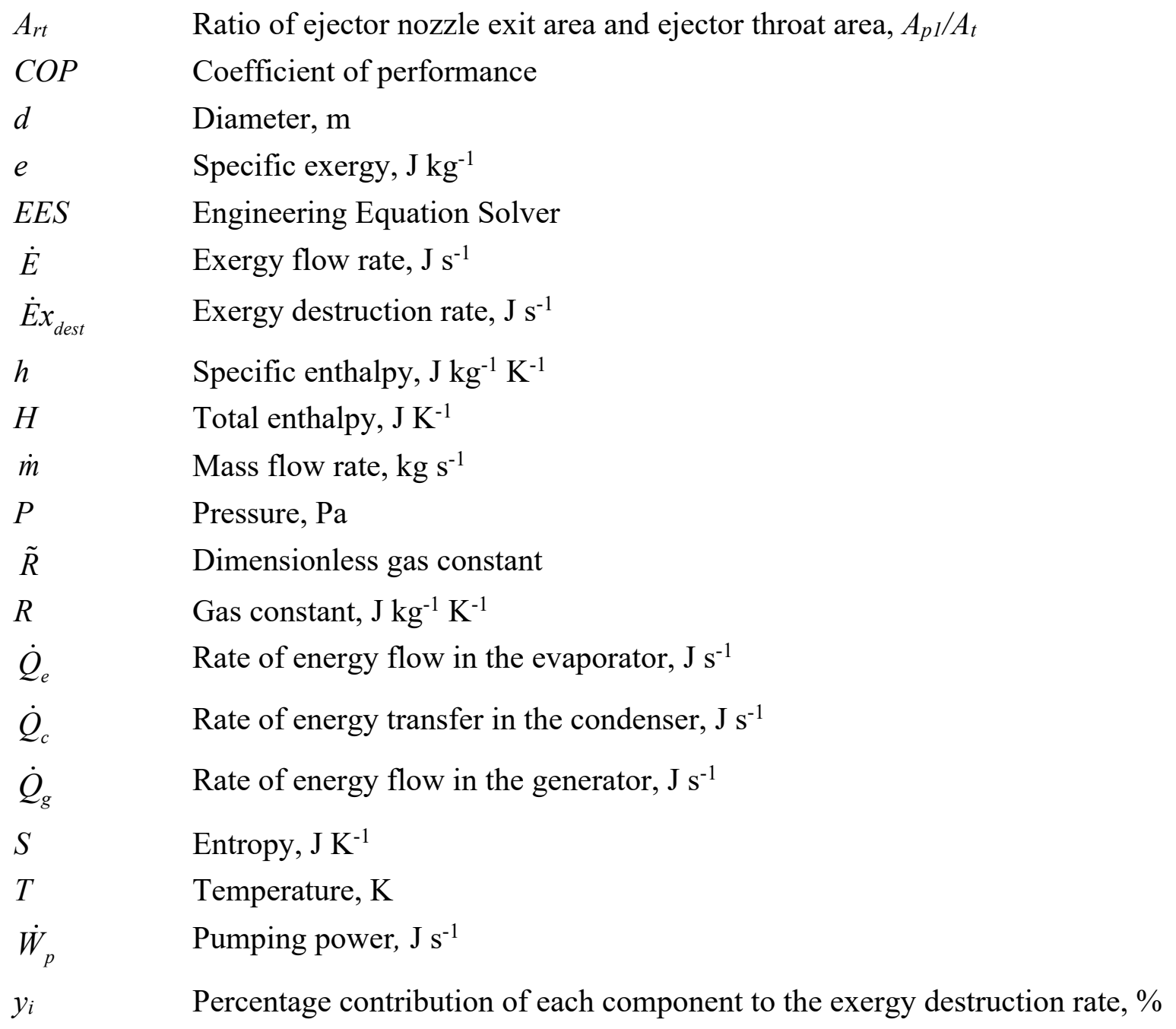

\section{Greek Symbols}

$\phi_{p} \quad$ Loss coefficient between the nozzle exit and mixing section

$\phi_{m} \quad$ Mixing loss coefficient

$\phi_{m p} \quad$ Mixing loss coefficient for the breakdown model

$\eta_{p} \quad$ Primary flow nozzle efficiency

$\eta_{s} \quad$ Secondary flow nozzle efficiency

$\eta_{e x} \quad$ Exergy efficiency

$\eta_{I I} \quad$ Second law efficiency

$\mu \quad$ Entrainment ratio

\section{Subscripts}

$\begin{array}{ll}c & \text { Condenser } \\ c b & \text { Ejector breakdown point }\end{array}$




\begin{tabular}{|c|c|}
\hline$c c$ & Critical point \\
\hline $\mathrm{CH}$ & Chemical exergy \\
\hline$c i$ & Condenser inlet \\
\hline co & Condenser exit \\
\hline dest & Destruction of exergy \\
\hline$e$ & Evaporator \\
\hline$e i$ & Evaporator inlet \\
\hline$e o$ & Evaporator outlet \\
\hline$g$ & Generator \\
\hline$g i$ & Generator inlet \\
\hline go & Generator outlet \\
\hline gh,in & Generator hot stream inlet \\
\hline gh,out & Generator hot stream outlet \\
\hline in & Inlet \\
\hline$K E$ & Kinetic energy \\
\hline$m$ & Mixing/mixed flow \\
\hline$o$ & Dead state \\
\hline opt & Optimal value \\
\hline out & Outlet \\
\hline$p$ & Primary flow \\
\hline$P E$ & Potential energy \\
\hline$P H$ & Physical exergy \\
\hline$p i$ & Pump inlet \\
\hline po & Pump exit \\
\hline$p 1$ & Nozzle exit \\
\hline$r i$ & Evaporator cooled water inlet \\
\hline ro & Evaporator cooled water outlet \\
\hline$s$ & Secondary flow/position of shock \\
\hline$t$ & Nozzle throat \\
\hline tot & Total \\
\hline$w i$ & Condenser cooling water inlet \\
\hline wo & Condenser cooling water outlet \\
\hline 1 & Nozzle exit \\
\hline 2 & Mixing plane in the constant area section \\
\hline 3 & Diffuser inlet \\
\hline
\end{tabular}

\subsection{Introduction}


Access to modern energy services remains an important factor as both developed and developing nations strive to achieve increased industrialization, increased economic growth and better standards of living. The demand for energy continues to grow as countries develop and as the global population continues to increase. Among the drivers of this demand is the need to maintain comfortable living spaces and the preservation of food. In developed countries, about $40 \%$ of the total energy supply is used by heating, air conditioning, and refrigeration (HVAC\&R) systems in both the residential and service sectors (Edberg et al., 2012). Globally, about 36\% of the total energy is used in buildings, accounting for around $40 \%$ of the overall $\mathrm{CO}_{2}$ emissions (IEA, 2019). The current HVAC\&R systems rely mainly on the vapor compression cycle powered by electrical energy generated largely from fossil fuels, and they require working fluids, most of which possess significant global warming potential (GWP). With these challenges, research efforts in HVAC\&R are focused on developing systems that use sustainable, clean and renewable energy resources as well as systems that use working fluids that are not detrimental to the environment. Technologies less reliant on fossil fuels and capable of using low cost and readily available renewable energy resources as well as low grade waste heat are increasingly being developed and deployed (Ullah et al., 2013). Moreover, the rising regulatory pressures also necessitate that ozone depleting and high GWP refrigerants are not used in new systems (Regulation (EU) No. 517/2014). The ejector refrigeration system is one of these systems that has shown potential as a simple, low cost and highly durable system. It does not have any moving parts and can be activated by readily available low grade heat sources (Martel and Parakh, 2015). Moreover, it is also simpler than other thermally activated refrigeration systems such as the absorption and adsorption refrigeration systems. An ejector can operate in the critical or the subcritical mode. In the critical mode of operation, both the primary flow and secondary flow are choked and is the on-design condition of the ejector. In the subcritical mode, only the primary flow is choked, and performance reduces with increasing backpressure.

Several investigations on the performance of ejector refrigeration systems, both experimental and theoretical have been undertaken by different researchers. The current advances in the study of ejectors by both modeling and experimentation have been recently presented by Aidoun et al. (2019). Huang et al. (1999) experimentally investigated the energetic performance an ejector refrigeration system using R141b working in only the critical mode of operation. García del Valle et al. (2014) presented a study on the experimental investigation of an ejector working with R134a 
aiming at improving its pressure recovery. Eames et al. (1995) presented a theoretical and experimental investigation of on energetic performance of an ejector refrigerator using steam. Cardemil and Colle (2012) presented a general model for performance investigation of vapor ejectors with $\mathrm{R} 141 \mathrm{~b}$, steam, and $\mathrm{CO}_{2}$ as working fluids. Zegenhagen and Ziegler (2015) considered a one-dimensional model of a jet-ejector working in the critical double choking mode with R134a as the refrigerant. Dennis et al. (2015) developed an algorithm for the design of the primary nozzle while considering changing throat sizes and exit diameters for an ejector using R245fa.

The influence of geometry on ejector performance has been considered and investigated in a number of studies. Aphornratana et al. (2001) experimentally investigated the influence of mixing chamber geometry on system performance for an ejector working with R11. Considering the constant area inlet and convergent inlet mixing chambers, the convergent chamber did not show any choking of the working fluid while choking was achieved with the constant area inlet chamber. Zhang et al. (2017) considered the influence of nozzle position on the design of a high-performance ejector working with R600a. They showed that there was an optimal nozzle position that maximizes performance. Thongtip and Aphornratana (2017) studied the impact of nozzle geometry on the performance of an ejector using R141b as the refrigerant. Wang et al. (2017) investigated an ejector with an auto-tuning capability to regulate the performance of a multi-effect distillation-thermal vapor compression desalination system. An optimal nozzle exit position was shown to exist and a correlation between the optimum nozzle exit position and the primary pressure was presented. As these studies show, ejector geometry plays a crucial role in determining how a given ejector will perform.

Advances aimed at improving the performance of the ejector refrigeration systems have been undertaken in a number of studies. Yang et al. (2012) considered the mixing process in a steam ejector of different nozzle structures. Conical, elliptical, square, rectangular and cross-shaped nozzles were considered. The conical nozzle showed better entrainment ratios than the other structures considered. Chen et al. (2018) considered ejector refrigeration systems using two-stage ejectors in the design and off-design conditions. Using two stage ejectors was shown to extend the ejector operation range in the off-design mode. An ejector with a swirl generator was recently considered in a study by Parveen Banu and Mani (2019). The increasing swirl intensity was shown to increase performance up to $15 \%$. Using an ejector with a movable spindle to vary the geometry of the ejector, Tashtoush and Algharbawi (2019) showed that performance increases by up to 78\% 
as the area ratio increases by $45 \%$. The latest advances in ejector modeling and experimentation and other performance enhancements have been presented by Aidoun et al. (2019). In addition, studies combining the ejector with other conventional technologies were reviewed and presented. With these advances in ejector design, performance of ejector refrigeration systems is continually improving, further increasing interest in the technology.

Exergetic performance analyses of ejector refrigeration systems are aimed at identifying losses in components or systems and suggesting ways to minimize these losses. Pridasawas and Lundqvist (2004) considered performance of a solar driven ejector refrigeration system with butane as the working fluid. For the ejector subsystem, the ejector showed the highest exergetic losses followed by the generator. Conventional and advanced exergy analyses of an ejector refrigeration system were presented by Chen et al. (2015) for an ejector using R245fa. The ejector was shown to have the highest exergy losses, about $53.6 \%$ followed by the generator, then the condenser. Alexis (2005) presented an exergetic analysis of an ejector refrigeration system with water as the working fluid. The ejector gave the largest exergy loss of $54 \%$, with the condenser giving the second largest contribution of $27 \%$. In a related study, Dai et al. (2009) considered a combined power and ejector refrigeration cycle. In the analysis of exergetic losses, the boiler and the ejector showed the greatest losses. In other studies, the ejector's contribution to the exergy losses was shown to be as high as 80\% (Ziapour and Abbasy, 2010). Untea et al. (2013) considered the energy and exergy analysis of an ejector refrigeration system using water, methanol, ammonia, and R134a as refrigerants. The ejector was shown to contribute over $80 \%$ of all the exergy losses in the system. As shown in these studies, the exergy destruction rate depends on the type of working fluid considered with some refrigerants giving contributions as high as $80 \%$ while others are at about $50 \%$ in the ejector. It is therefore essential that for each refrigerant used in the system, exergy losses are determined for the performance of each component to be characterized.

In most of the studies reviewed in the preceding paragraphs and as shown in the comprehensive reviews of ejector refrigeration by Besagni et al. (2016) and recently by Aidoun et al. (2019), refrigerants that are currently banned or ones that will be replaced gradually such as R141b, R123, R245fa, R22, R11, R152a, and R134a (Ozone Secretariat, 2018; Regulation (EU) No. 517, 2014; Linde, 2019; Chen et al., 2014) have been considered. While these refrigerants give somewhat better performance, they are either ozone depleting or possess high GWP. Other working fluids 
such as R600, R600a, and R290 have been investigated, but these are highly flammable and should be used with extra care.

Given the limitations of the conventional refrigerants, there are increased efforts to develop working fluids with better thermodynamic performance that are less harmful to the environment. Among these new working fluids, Hydrofluoroolefin (HFO) refrigerants and Hydrochlorofluoroolefins (HCFO), are new groups of refrigerants with no ODP and very small GWPs (Makhnatch et al., 2014; Chen et al., 2014; Honeywell, 2015). They have the potential to replace the current refrigerants with high GWPs in HVAC\&R systems. A study that considered the use of environmentally benign refrigerants in an ejector system was presented by Chen et al. (2014). They considered R134a, R152a, R290, R430A, R245fa, R600, R600a and R1234ze as refrigerants. This study introduced the performance with an HFO refrigerant, R1234ze that had not been considered prior to their study. It has no ODP and has a nearly zero GWP. R1234ze gave the highest COP as 0.33 compared to 0.28 for R134a and 0.25 for R152a, showing the potential of this HFO refrigerant over conventional ones with higher GWP values. In a recent study by Śmierciew et al. (2017), the use of HFO-1234ze(E) in an ejector refrigeration system was investigated. In another recent study, Atmaca et al. (2017) considered an ejector refrigeration system working with R1234yf and R1234ze(E) and R134a. R1234yf gave COPs closer to those of R134a.

There is a considerable number of HFO and HCFO refrigerants available today (Kopchick and Scancarello, 2017), however, studies on their use in ejector refrigeration systems are still limited in the literature. The energetic and exergetic performance of these refrigerants has also not been widely investigated. Moreover, it has been shown that the ejector performance depends on the considered working fluid (Saleh, 2016). In addition, as pointed out in Mwesigye and Dworkin (2018), there is a lack of models that accurately predict performance of ejector refrigeration system in both the critical and subcritical mode. Most models available in the literature assume constant ejector loss coefficients and result in significant errors (Huang et al., 1999; Chen et al., 2013).

In a recent investigation using a novel and more accurate model for ejector performance investigation, HCFO-1233zd(E) and $\mathrm{HFO}-1234 \mathrm{ze}(\mathrm{Z})$ were shown to offer higher performance than R141b and R245fa (Mwesigye and Dworkin, 2018). However, in this preliminary investigation, no optimization of system performance was done and only the first law of 
thermodynamics was used. As such, the main purpose of this study is to use a precise model and investigate in detail, the energetic and exergetic performance of an ejector refrigeration system utilizing a new refrigerant - R1233zd(E) as the working fluid. R1233zd(E) is among the new environmentally benign refrigerants with no ODP and very low GWP and has been not widely investigated for use in ejector refrigeration systems. Furthermore, in this study, the optimal generator temperatures, optimal COP and the critical condensing temperatures are obtained and presented for the considered area ratios. Moreover, new correlations for the optimal generator temperature and optimal COP have also been derived and presented helping designers determine ejector optimal operational conditions.

\subsection{Ejector refrigeration system}

The components of an ejector refrigeration system and the ejector are shown in Figs. 1 and 2, respectively. In the ejector refrigeration system shown in Fig. 1, the ejector is a critical component affecting performance. A high pressure and high temperature vapor from the generator enters the nozzle through which it expands. As it expands, supersonic flow is achieved within the nozzle producing a low-pressure region around the nozzle and allowing for the entrainment of the low-

pressure secondary flow in the ejector (Eames et al., 1995). The primary and secondary flow merge in the mixing chamber of the ejector and exit through the condenser (Fig. 2). The resulting vapor condenses to liquid and a feed-pump delivers part of this liquid to the generator. The remaining fluid, the amount of which depends on the evaporator conditions, passes through a throttle valve or an expansion valve and expands to the evaporator pressure. The respective states at the inlet and exit of each component in the system are labelled in Fig. 2. For the condenser, the primary flow inlet and exit states are $c i$ and $c o$, respectively. The condenser cooling water inlet and exit states are $w i$ and $w o$, respectively. For the evaporator, the secondary flow inlet and exit states are $e i$ and eo. The evaporator cooled water inlet and exit states are $r i$ and $r o$, respectively. For the generator, the primary flow inlet and exit states are $g i$ and go, the heat supply to the generator is through the hot fluid with gh,in and gh,out, as the inlet and exit states, respectively.

The ejector shown in Fig. 2 is made up of three main sections, namely: a suction chamber with a nozzle, the constant area section, and the diffuser section. Within the ejector, suction, mixing and compression occur resulting in the entrainment of the secondary flow, mixing of the secondary 
flow with the primary flow and increase of mixture pressure, respectively (Eames et al., 1995). The different sections of the ejector are shown in Fig. 2.

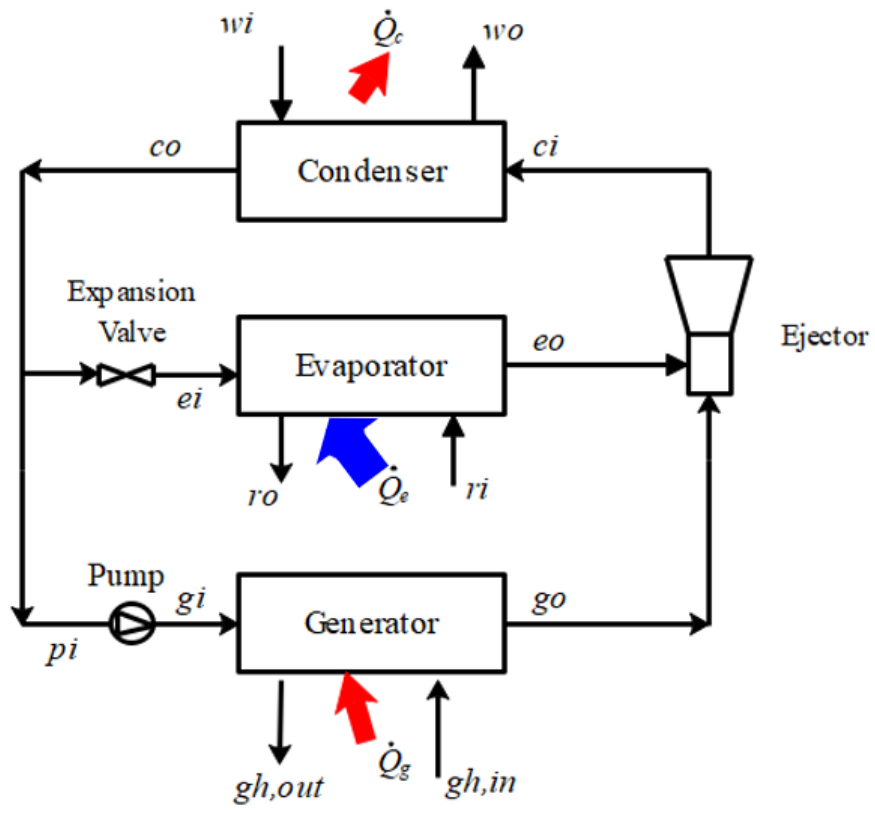

Fig. 1. Schematic representation of an ejector refrigeration system

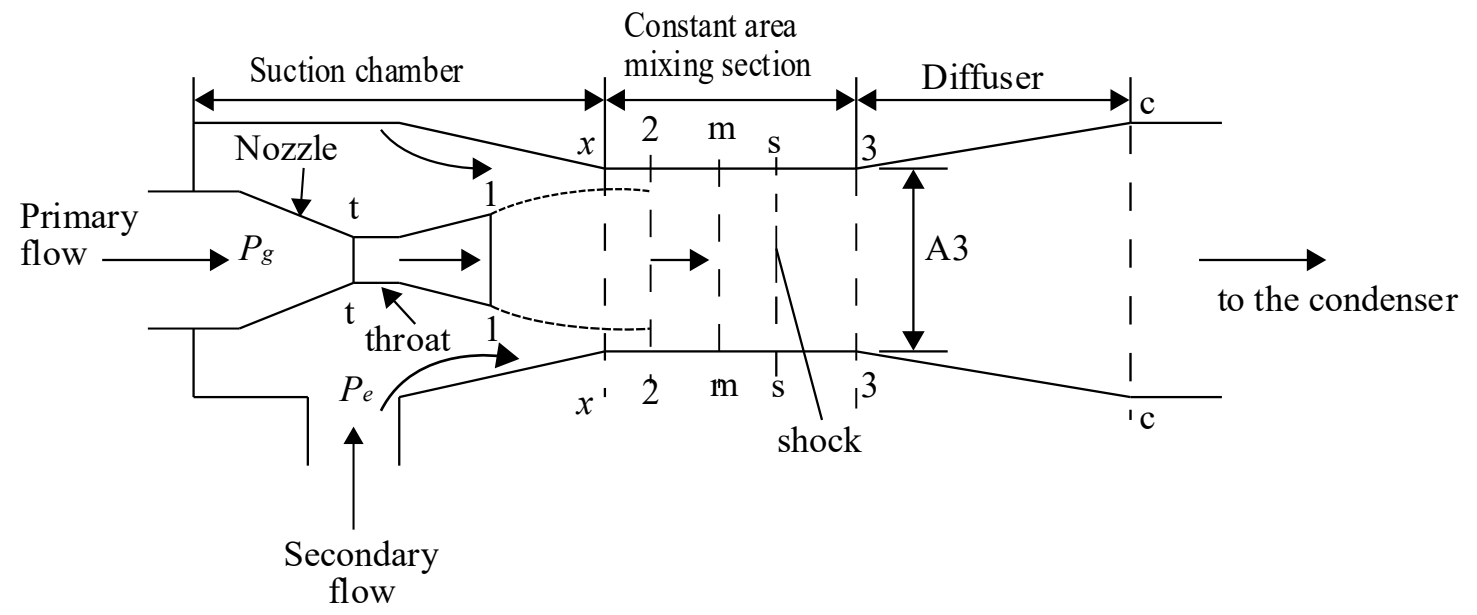

Fig. 2. Representation of the different sections of an ejector (suction chamber with nozzle, constant area mixing section and diffuser)

\subsection{Theoretical model development}

A detailed and improved model derived in the authors' earlier work (Mwesigye and Dworkin, 2018) that predicts ejector performance more precisely has been used in this investigation. The model is based on the constant pressure mixing theory which is widely used in the study of ejector systems (Chen et al., 2013; Huang et al., 1999; Li et al., 2017b). The model was shown to predict 
ejector performance for dry and isentropic working fluids having compressibility factors close to those of R141b and R245fa, within $\pm 11 \%$ (Mwesigye and Dworkin, 2018). Unlike most models that assume constant ejector coefficients, the new model used in this work uses correlations for ejector coefficients and determines ejector performance in all the modes of operation - both critical and subcritical. A detailed description of the model can be found in the authors' previous work (Mwesigye and Dworkin, 2018).

\subsection{Ejector model}

In the ejector, the primary flow is decelerated, while the secondary flow is accelerated into the vacuum space within the ejector such that mixing takes place at equal pressures (Keenan et al., 1950). An ejector can operate in two modes, i.e. critical mode (double choking) or the subcritical mode with single flow choking as depicted in Fig. 3 (Mohammadi, 2019). The entrainment ratio $(\mu)$ remains constant in the critical mode of operation and the condensing pressure $\left(P_{c}\right)$ is lower than the critical condensing pressure $\left(P_{c c}\right)$.

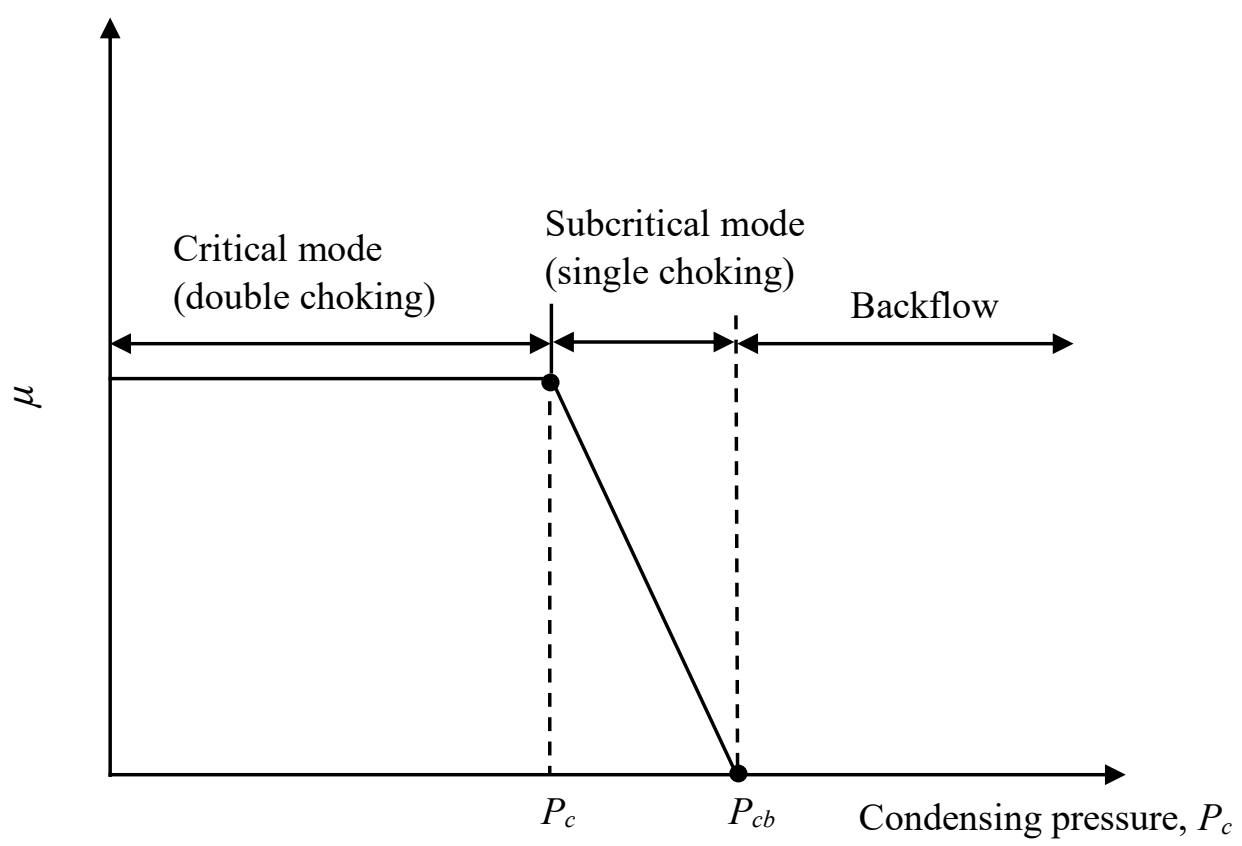

Fig. 3. Operation modes of an ejector

In the subcritical mode, the entrainment ratio reduces from the critical value to zero at the ejector breakdown pressure $\left(P_{c b}\right)$ as the condensing pressure increases. As the condensing pressure increases to values above the breakdown pressure, there is backflow and the ejector stops working. 
In Fig. 3, the condensing pressure can be replaced by the condensing temperature on the $x$-axis and the critical condensing temperature $T_{c c}$ and the breakdown temperature $T_{c b}$ corresponding to $P_{c c}$ and $P_{c b}$, respectively, shown. The detailed equations defining the performance of an ejector in both modes of operation together with the assumptions used can be found in the authors' previous study (Mwesigye and Dworkin, 2018). The model is rather comprehensive and long and has not been repeated in its entirety in this work. In this section, only the key parameters i.e. the primary mass flow rate, the secondary mass flow rate and the intermediate parameters that enable the determination of the ejector performance are presented. Interested readers can find the detailed model in Mwesigye and Dworkin (2018).

The primary mass flow rate is given by (Huang et al., 1999; Mwesigye and Dworkin, 2018)

$$
\dot{m}_{p}=P_{g} \frac{A_{t}}{\sqrt{T_{g}}} \sqrt{\frac{k}{R}\left(\frac{2}{k+1}\right)^{(k+1) /(k-1)}} \sqrt{\eta_{p}}
$$

where $P_{g}$ and $T_{g}$ are the specified generator pressure and temperature, $A_{t}$ represents the primary nozzle throat area, $k$ is the heat capacity ratio, $R$ is the specific gas constant and $\eta_{p}$ is the primary nozzle efficiency widely used as 0.95 .

The secondary mass flow rate is determined according to (Huang et al., 1999; Mwesigye and Dworkin, 2018)

$$
\dot{m}_{s}=\frac{P_{e} A_{2 s}}{\sqrt{T_{e}}} \sqrt{\frac{k}{R}\left(\frac{2}{k+1}\right)^{(k+1) /(k-1)}} \sqrt{\eta_{s}}
$$

with $\eta_{s}$ as the secondary flow efficiency taken as 0.85 as is widely used, $P_{e}$ is the evaporator pressure, $T_{e}$ is the evaporator temperature and $A_{2 s}$ is the exit area of the secondary flow at the mixing plane. $A_{2 s}$ is obtained from the dimensions of the mixing chamber and the area occupied by the primary flow at mixing according to $A_{3}=A_{2 p}+A_{2 s}$. Since the dimensions of the mixing chamber are known, only $A_{2 p}$ is needed to determine $A_{2 s}$ in Eqn. (2). It is given as (Huang et al., 1999; Mwesigye and Dworkin, 2018)

$$
\frac{A_{2 p}}{A_{p 1}} \approx \frac{\left(\phi_{p} / M_{2 p}\right)\left(\left(\frac{2}{k+1}\right)\left(1+\frac{(k-1)}{2} M_{2 p}^{2}\right)\right)^{(k+1) /(2(k-1))}}{\left(1 / M_{p 1}\right)\left(\left(\frac{2}{k+1}\right)\left(1+\frac{(k-1)}{2} M_{p 1}^{2}\right)\right)^{(k+1) /(2(k-1))}}
$$


where $A_{p l}$ is the area at the primary nozzle exit, $\phi_{p}$ is the loss coefficient for the primary flow through the nozzle, $M_{2 p}$ is the Mach number of the primary flow at the mixing plane, $M_{p 1}$ is the Mach number of the nozzle exit.

When the primary and the secondary flow mix, the momentum balance gives the velocity of the resulting mixture and the energy balance gives the corresponding temperature. Momentum balance gives

$$
\phi_{m}\left(\dot{m}_{p} u_{2 p}+\dot{m}_{s} u_{2 s}\right)=\left(\dot{m}_{p}+\dot{m}_{s}\right) u_{m}
$$

in which $\phi_{m}$ represents the loss coefficient incorporating the friction losses during mixing. With $u_{2 p}, u_{2 s}$ and $u_{m}$ the primary, secondary and mixture velocities, respectively. They are obtained from the respective Mach numbers and the corresponding sound speeds together with the energy balance for the mixing process (Huang et al., 1999; Mwesigye and Dworkin, 2018). The energy balance at mixing is

$$
\dot{m}_{p}\left(c_{p} T_{2 p}+\frac{u_{2 p}^{2}}{2}\right)+\dot{m}_{s}\left(c_{p} T_{2 s}+\frac{u_{2 s}^{2}}{2}\right)=\left(\dot{m}_{p}+\dot{m}_{s}\right)\left(c_{p} T_{m}+\frac{u_{m}^{2}}{2}\right)
$$

To predict ejector performance more precisely, the model uses loss coefficients that are functions of the area ratio (the ratio of the mixing chamber cross-section area to the nozzle throat crosssection area) and the generator to evaporator pressure ratio (pressure lift) rather than constant values. The ejector loss coefficients, $\phi_{p}$ and $\phi_{m}$ found in Eqns. (3) and (4), respectively and in the mixing equation for the ejector breakdown model, $\phi_{m p}$ have been determined to be (Mwesigye and Dworkin, 2018)

$$
\begin{aligned}
& \phi_{p}=1.139+0.01768 \frac{A_{3}}{A_{t}}-0.009797 \frac{P_{g}}{P_{e}}-1.08 \tilde{R} \\
& \phi_{m}=0.8264-0.01254 \frac{A_{3}}{A_{t}}+0.005804 \frac{P_{g}}{P_{e}}+0.4589 \tilde{R} \\
& \phi_{m p}=0.8802-0.09203 \frac{A_{r}}{A_{r t}}+0.00158\left(\frac{P_{g}}{P_{e}}\right)^{k}
\end{aligned}
$$

$\phi_{p}$ is the nozzle loss coefficient, $\phi_{m}$ is the mixing loss coefficient, and $\phi_{m p}$ is the mixing loss coefficient for the ejector breakdown model. The non-dimensionalized gas constant used in Eqs. (6) and (7), $\tilde{R}$ is the ratio of the refrigerant's specific gas constant to that of air. Equations (6) - (8) 
are valid for $6.44 \leq A_{r} \leq 12.89,8{ }^{\circ} \mathrm{C} \leq T_{e} \leq 16{ }^{\circ} \mathrm{C}$ and $78{ }^{\circ} \mathrm{C} \leq T_{g} \leq 100{ }^{\circ} \mathrm{C}$. When used with dry and isentropic working fluids such as R1233zd(E), R365mfc, RE245fa2 and other refrigerants whose compressibility factors are close to those of R141b and R245fa. The model developed with these equations has been validated and the results were shown to be valid within $\pm 11 \%$ (Mwesigye and Dworkin, 2018).

\subsection{Coefficient of performance}

The performance of an ejector system is given in terms of the entrainment ratio, which is the ratio of the entrained secondary fluid mass flow rate to the primary fluid mass flow rate. However, a more practical term to use is the COP. It relates the desired effect (cooling if used for refrigeration) to the energy input into the system and is defined as

$$
C O P=\frac{\dot{Q}_{e}}{\dot{Q}_{g}+\dot{W}_{p}}
$$

In which, $\dot{Q}_{e}$ is the cooling capacity given by

$$
\dot{Q}_{e}=\dot{m}_{s}\left(h_{e o}-h_{e i}\right)
$$

Where $h_{e o}$ and $h_{e i}$, are the enthalpies at the exit and inlet of the evaporator.

The rate at which energy is transferred to the generator is determined as

$$
\dot{Q}_{g}=\dot{m}_{p}\left(h_{g o}-h_{g i}\right)
$$

Where $h_{g o}$ and $h_{g i}$, are the enthalpies at the exit and inlet of the generator.

The work input to the pump is given by

$$
\dot{W}_{p}=\dot{m}_{p}\left(h_{g i}-h_{c o}\right)
$$

In which, $h_{c o}$ is the enthalpy at the condenser exit. Simplifying Eqns. (9)-(12) gives

$$
C O P=\mu \frac{\left(h_{e o}-h_{e i}\right)}{\left(h_{g o}-h_{c o}\right)}
$$

In Eq. (13), $\mu$ is the entrainment ratio, defined as $\dot{m}_{s} / \dot{m}_{p}$. It is either the critical entrainment ratio or the subcritical entrainment ratio depending on the mode of operation (Mwesigye and Dworkin, 2018). At the generator and the evaporator exits, the vapor is saturated. After condensation, the 
liquid enters the throttle valve as a saturated liquid while the liquid entering the vapor generator is a compressed liquid.

\subsection{Thermodynamic performance investigation using the exergy analysis method}

The second law of thermodynamics, which is used to determine the quality of energy delivered by systems has proved to be a powerful tool in the design, analysis and optimization of energy systems. Exergy arising from the second law can be defined as the work potential of a system in a definite environment and can be thought of as the maximum amount of useful work that a system is able to give as it is brought in equilibrium with the surrounding environment. An exergy analysis makes it possible to determine the exergy losses (true thermodynamic losses) in processes, system components and systems.

For a system, the exergy is obtained from different contributions. In the absence of magnetic, nuclear and surface tension effects, the remaining components are: physical exergy $\left(\dot{E}_{P H}\right)$, kinetic exergy $\left(\dot{E}_{K E}\right)$, chemical exergy $\left(\dot{E}_{C H}\right)$, and potential exergy $\left(\dot{E}_{P E}\right)$. These contributions give the total exergy as

$$
\dot{E}_{t o t}=\dot{E}_{P H}+\dot{E}_{K E}+\dot{E}_{P E}+\dot{E}_{C H}
$$

For a control volume at steady state, the exergy balance is composed of several terms. The exergy destroyed is obtained from the differences in streams of exergy flow, heat transfer exergy flows, and work exergy flows as

$$
\dot{E} x_{d e s t}=\sum \dot{E} x_{i n}-\sum \dot{E} x_{o u t}+\sum\left[\dot{Q}\left(1-\frac{T_{o}}{T}\right)_{\text {in }}\right]-\sum\left[\dot{Q}\left(1-\frac{T_{o}}{T}\right)_{\text {out }}\right]+\sum \dot{W}_{\text {in }}-\sum \dot{W}_{\text {out }}
$$

In the ejector refrigeration system, the other components of exergy are negligible compared with the physical exergy. Therefore, only the physical exergy is considered. The exergy streams into and out of the system in this case would only be made up of the physical exergy terms in the absence of kinetic, potential and chemical exergy.

The physical exergy for a stream entering or leaving the system (flow exergy) is obtained as

$$
\dot{E}_{P H}=\left(H-H_{o}\right)-T_{o}\left(S-S_{o}\right)
$$

The dead state temperature $T_{o}$, has been taken as $298.15 \mathrm{~K}$. The specific exergy is the total exergy divided by the mass flow rate. Thus, the specific physical exergy is given by 


$$
e_{P H}=\left(h-h_{o}\right)-T_{o}\left(s-s_{o}\right)
$$

Using Eqns. (14) - (17), the exergy destruction in each component of the ejector refrigeration system shown in Fig. 1 can be determined using the states indicated in the figure. For the pump, there is no energy transfer by heat into or out of the control volume representing the pump. Thus, pump exergy destruction is

$$
\dot{E} x_{d e s t, p}=\dot{m}_{p}\left(e_{p i}-e_{p o}\right)+\dot{W}_{p}
$$

The specific exergies at the inlet and exit of the pump, $e_{p i}$ and $e_{p o}\left(=e_{g i}\right)$ in Eq. (18) can be determined accordingly using Eqn. (17). Similarly, using Eqn. (15) the exergy destruction rates for other components can be obtained.

For the generator, the exergy destruction rate is given by

$$
\dot{E} x_{d e s t, g}=\dot{m}_{p}\left(e_{g i}-e_{g o}\right)+\dot{Q}_{g}\left(1-\frac{T_{o}}{T_{g}}\right)
$$

Alternatively, if the generator receives streams of hot air or water or any other working fluid and is modelled as being adiabatic (no energy losses across the boundary of the control volume), then the exergy balance gives

$$
\dot{E} x_{d e s t, g}=\dot{m}_{p}\left(e_{g i}-e_{g o}\right)+\dot{m}_{g}\left(e_{g h, \text { in }}-e_{g h, o u t}\right)
$$

The terms, $e_{g h, \text { in }}$ and $e_{\text {gh,out }}$ represent the exergy flows from the hot stream into and out of the generator, respectively.

The exergy destruction rate in the evaporator is

$$
\dot{E} x_{d e s t, e v a}=\dot{m}_{s}\left(e_{e i}-e_{e o}\right)+\dot{Q}_{e}\left(1-\frac{T_{o}}{T_{e}}\right)
$$

For known streams into and out of the evaporator, the exergy destruction is

$$
\dot{E} x_{d e s t, e v a}=\dot{m}_{s}\left(e_{e i}-e_{e o}\right)+\dot{m}_{e}\left(e_{r i}-e_{r o}\right)
$$

In which the subscripts $e i$, eo, $r i$ and ro represent the evaporator inlet, evaporator outlet, the refrigerated water inlet and refrigerated water outlet, respectively.

The exergy balance for the condenser gives 


$$
\dot{E} x_{d e s t, c o n}=\left(\dot{m}_{p}+\dot{m}_{s}\right)\left(e_{c i}-e_{c o}\right)-\dot{Q}_{c}\left(1-\frac{T_{o}}{T_{c}}\right)
$$

Note that energy transfer by heat is from the condenser to the surroundings. Thus, the energy transfer rate term $\left(\dot{Q}_{c}\right)$ in Eqn. (23) is accompanied by a negative sign. For known stream temperatures into and out of the condenser and with no heat transfer across the boundaries of the condenser, the exergy destruction rate is

$$
\dot{E} x_{d e s t, c o n}=\left(\dot{m}_{p}+\dot{m}_{s}\right)\left(e_{c i}-e_{c o}\right)+\dot{m}_{c}\left(e_{w i}-e_{w o}\right)
$$

The terms $e_{w i}$ and $e_{w o}$ represent the exergy flow rates for the incoming and exit water used to cool the refrigerant in the condenser.

For the expansion valve, there is no energy transfer by heat or work. Therefore, the exergy balance gives

$$
\dot{E} x_{d e s t, \exp }=\dot{m}_{s}\left(e_{x i}-e_{x o}\right)
$$

The ejector is assumed to operate adiabatically such that the exergy balance gives

$$
\dot{E} x_{d e s t, e j}=\dot{m}_{p} e_{g o}+\dot{m}_{s} e_{e o}-\left(\dot{m}_{p}+\dot{m}_{s}\right) e_{c i}
$$

Using Eqns. (17) to (26), the total exergy destruction rate in the entire system as represented in Fig. 1 is then obtained as

$$
\dot{E} x_{d e s t, t o t}=\dot{E} x_{d e s t, p}+\dot{E} x_{d e s t, g}+\dot{E} x_{d e s t, e v a}+\dot{E} x_{d e s t, c o n}+\dot{E} x_{d e s t, \exp }+\dot{E} x_{d e s t, e j}
$$

The total exergy destroyed during the cycle is either zero for a perfect system (the case of an ideal system with no irreversibilities) or positive for a realistic system. It is therefore expected that the exergy destruction rate in the components of the system and the entire system is greater than zero owing to the considered inefficiencies in the processes and components.

For the entire system, the exergy efficiency is defined as

$$
\eta_{e x}=1-\frac{\dot{E} x_{d e s t, t o t}}{\dot{m}_{g} e_{g h, i n}+\dot{W}_{p}}
$$

For steady flow devices as is the case of the ejector refrigeration system, the second law efficiency is obtained as the ratio of the exergy recovered to the exergy supplied. With this, the second law efficiencies for each component can be determined. 
The second law efficiencies for each component are given as:

Pump:

$\eta_{I I, p}=\frac{\dot{m}_{p}\left(e_{p o}-e_{p i}\right)}{\dot{W}_{p}}$

generator:

$\eta_{I I, g}=\frac{\dot{m}_{p}\left(e_{g o}-e_{g i}\right)}{\dot{m}_{g}\left(e_{g h, \text { in }}-e_{g h, o u t}\right)}$,

condenser:

$\eta_{I I, c}=\frac{\left(\dot{m}_{p}+\dot{m}_{s}\right)\left(e_{c i}-e_{c o}\right)}{\dot{m}_{c}\left(e_{w i}-e_{w o}\right)}$,

ejector:

$$
\eta_{I I, e j}=\frac{\left(\dot{m}_{p}+\dot{m}_{s}\right) e_{c i}}{\dot{m}_{p} e_{g o}+\dot{m}_{s} e_{e o}}
$$

and evaporator:

$$
\eta_{I I, e v}=\frac{\dot{m}_{e}\left(e_{r i}-e_{r o}\right)}{\dot{m}_{s}\left(e_{e i}-e_{e o}\right)}
$$

It is also useful to determine the contribution of each component to the total exergy destruction rates of the system. The percentage contribution by a component $i$ to the total exergy destruction rate is

$$
y_{i}=\frac{\dot{E} x_{d e s t, i}}{\dot{E} x_{d e s t, t o t}}
$$

For example, the fraction of the total exergy destruction rate that comes from the ejector is given by

$$
y_{e j}=\frac{\dot{E} x_{d e s t, e j}}{\dot{E} x_{d e s t, t o t}}
$$

The fraction of other components can be determined accordingly. 


\subsection{Working fluid}

In this study, an HCFO refrigerant with a very low GWP and no ODP, R1233zd(E) has been considered based on the potential it exhibited in a preliminary analysis of an ejector refrigeration system using different working fluids (Mwesigye and Dworkin, 2018). R1233zd(E) provided better performance than $\mathrm{R} 141 \mathrm{~b}$ and $\mathrm{R} 245 \mathrm{fa}$, the commonly used refrigerants in ejector refrigeration systems (Mwesigye and Dworkin, 2018). Table 1 shows the relevant properties of R1233zd(E) in comparison with other refrigerants (A-Gas(R), 2018; Makhnatch et al., 2014; Linde, 2019; Honeywell, 2015; UNEP Ozone Secretariat, 2018; UNEP Ozone Action Branch, 2009). As shown, the refrigerant has a critical temperature and critical pressure close to those of R245fa, but lower than those of R141b. Evidently, the environmental properties of R1233zd(E) are superior to those of R141b and R245fa.

$\mathrm{R} 1233 \mathrm{zd}(\mathrm{E})$ is a dry working fluid and has a shape on the $T-s$ diagram similar to that of R141b and R245fa (Mwesigye and Dworkin, 2018). Dry refrigerants are beneficial since they give higher values of the entrainment ratio compared to wet refrigerants (Li et al., 2017a). In addition, using dry working fluids ensures that there are no liquid droplets during expansion in the nozzle, eliminating the need for superheating the fluid entering the ejector. With no condensation in the nozzle there are less friction losses and therefore improved performance.

Table 1. Relevant properties of R1233zd(E) and other commonly used working fluids

\begin{tabular}{|c|c|c|c|c|c|c|c|c|}
\hline Refrigerant & $\begin{array}{l}\text { Molecular } \\
\text { Mass } \\
(\mathbf{k g} / \mathbf{k m o l})\end{array}$ & $\begin{array}{l}\text { Boling } \\
\text { point } \\
\left({ }^{\circ} \mathrm{C}\right)\end{array}$ & $\begin{array}{l}\text { Critical } \\
\text { Temperature } \\
\left({ }^{\circ} \mathrm{C}\right)\end{array}$ & $\begin{array}{l}\text { Critical } \\
\text { Pressure } \\
\text { (MPa) }\end{array}$ & $\begin{array}{l}\text { Fluid } \\
\text { type } \\
\text { (wet/dry) }\end{array}$ & $\begin{array}{l}\text { Safety } \\
\text { group }\end{array}$ & ODP & GWP \\
\hline $\mathrm{R} 141 \mathrm{~b}$ & 116.95 & 32.1 & 204.4 & 4.21 & dry & A2 & 0.11 & 725 \\
\hline $\mathrm{R} 245 \mathrm{fa}$ & 134.05 & 15.1 & 154.0 & 3.65 & dry & B1 & None & 1050 \\
\hline R123 & 152.90 & 27.9 & 184.0 & 3.70 & dry & B1 & $0.02-0.06$ & 77 \\
\hline R134a & 102.03 & -26.0 & 101.0 & 4.10 & wet & A1 & None & 1430 \\
\hline R1233zd(E) & 131.00 & 19.0 & 166.0 & 3.60 & dry & A1 & None & 4.5 \\
\hline RE245fa2 & 150.00 & 29.24 & 171.7 & 3.43 & dry & & None & 286 \\
\hline R600 & 58.12 & -0.53 & 152.0 & 3.80 & isentropic & A3 & None & 4 \\
\hline
\end{tabular}




\begin{tabular}{lllllllll}
\hline R600a & 58.12 & -11.68 & 134.7 & 3.64 & isentropic & A3 & None & 4 \\
R290 & 44.1 & -42.1 & 96.68 & 4.25 & wet & A3 & None & 3 \\
R1234ze(Z) & 114 & 9.28 & 150.1 & 3.53 & wet & A2L & None & 6 \\
R1234ze(E) & 114 & -19.28 & 109.4 & 3.63 & isentropic & A2L & None & 6 \\
\hline
\end{tabular}

\subsection{Solution methodology}

The solution methodology used in this study is based on the improved and novel ejector performance model developed in the authors' previous investigation (Mwesigye and Dworkin, 2018). In obtaining the solutions to the equations in the developed model, a computer program was developed in Engineering Equation Solver (EES) (EES, 2019). The program determines the performance of the ejector in the critical and subcritical modes of operation. The detailed model description and the solution methodology together with the solution flowchart can be found in (Mwesigye and Dworkin, 2018). The properties of interest at each state were determined using built-in thermophysical property functions in EES by specifying two independent and intensive properties. For example, at the generator inlet, the generator temperature is known, and the saturation pressure can be determined. Since the vapor was taken to enter the nozzle as a saturated, the quality is taken as 1 . Then, the other properties can be obtained. i.e. the entropy is $s=$ entropy $\left(\mathrm{R} 1233 \mathrm{zd}(\mathrm{E}), P=P_{g}, x=1\right)$.

Table 2 gives the ejector geometries used in this study. The choice of these ejector configurations is such that a wide range of area ratios can be investigated, while still providing better performance and reasonable critical condensing temperatures. Ejector geometries with area ratios between 6.25 and 10.64 were considered for parametric investigations in this study. The geometries of ejectors 1, 2, 3, and 4 shown in Table 2 were predetermined iteratively using the developed model considering the critical mode of operation. Moreover, the ejector geometries in the Huang et al. (1999) study were found to be appropriate for R1233zd(E), giving better performance for R1233zd(E) than R141b used in their study.

In addition to the ejector geometry, the generator temperature $\left(T_{g}\right)$ and the evaporator temperature $\left(T_{e}\right)$ are also known terms. The nozzle efficiencies for both the primary and the secondary flows were constant and taken as $\eta_{p}=0.95$ and $\eta_{s}=0.85$, respectively, in agreement with other studies (Chen et al., 2013; Huang et al., 1999; Li et al., 2017b). The other coefficients were evaluated using the developed correlations in Eqns. (6) - (8). Convergence was obtained when tight relative 
residuals of $10^{-7}$ and a change in variables after each iteration of $10^{-10}$ or less were reached. The complete model and solution procedure are thoroughly described in (Mwesigye and Dworkin, 2018).

Table 2. Ejector geometries considered in the study

\begin{tabular}{lcrrrr}
\hline Ejector & $d_{t}(\mathrm{~mm})$ & $d_{1}(\mathrm{~mm})$ & $d_{3}(\mathrm{~mm})$ & $A_{r}[-]$ & \\
\hline AA & 2.64 & 4.5 & 6.70 & 6.44 & Huang et al. (1999) \\
AC & 2.64 & 4.5 & 7.60 & 8.28 & Huang et al. (1999) \\
AD & 2.64 & 4.5 & 8.10 & 9.41 & Huang et al. (1999) \\
AG & 2.64 & 4.5 & 7.34 & 7.73 & Huang et al. (1999) \\
EH & 2.82 & 5.1 & 9.20 & 10.64 & Huang et al. (1999) \\
1 & 2.25 & 4.2 & 6.80 & 9.13 & Present study \\
2 & 3.15 & 5.6 & 9.25 & 8.62 & Present study \\
3 & 3.31 & 6.0 & 8.78 & 7.04 & Present study \\
4 & 3.65 & 6.5 & 10.00 & 7.51 & Present study \\
\hline
\end{tabular}

\subsection{Optimization approach}

The optimization of ejector performance was undertaken using the EES optimization toolbox using the min/max function (EES, 2019). The objective function considered was the COP and the independent variables were the ejector area ratio, the generator temperature, the evaporator temperature and the condensing temperature.

The COP was maximized each turn for a given condensing temperature subject to evaporator temperatures: $0{ }^{\circ} \mathrm{C} \leq T_{e} \leq 16{ }^{\circ} \mathrm{C}$, generator temperatures: $70{ }^{\circ} \mathrm{C} \leq T_{g} \leq 120{ }^{\circ} \mathrm{C}$, area ratios: $6.44 \leq A_{r} \leq 10.64$ and condensing temperatures: $25{ }^{\circ} \mathrm{C} \leq T_{c} \leq 40{ }^{\circ} \mathrm{C}$. With the ejector model implemented in EES, the Nelder-Mead Simplex method which optimizes a function of multiple variables without derivatives was used (EES, 2019). This method provides better performance than the other algorithms where it might be difficult to obtain derivatives of functions. The algorithm uses $N+1$ test points (where $\mathrm{N}$ is the degrees of freedom also called a simplex) to evaluate the objective function at each point (EES, 2019). The worst point is eliminated and a new point is found by reflecting away from the worst point about the axis formed by the remaining points (EES, 2019). This is repeated until the stopping criteria is achieved.

The optimization proceeds by choosing the variable to optimize and the independent variables to be considered. Then the upper and lower limits of the independent variables are specified, and reasonable guess values are specified. The optimization method is then specified, in this case 
Nelder-Mead Simplex method. The number of function calls was set to 500 with a conservative relative convergence tolerance of $1 \times 10^{-6}$ was used. With convergence, the relative change in the independent variables between successive steps is less than the stated tolerance. If the convergence criteria is not met, the number of function calls is increased.

\subsection{Validation of the developed models}

A thorough validation of the developed model used was presented in (Mwesigye and Dworkin, 2018). Using R $141 \mathrm{~b}$ as the refrigerant, the entrainment ratio was within $\pm 5.5 \%$ while the critical condensing temperatures were within $\pm 0.8^{\circ} \mathrm{C}$ of the experimental values in Huang et al. (1999). Moreover, the results were close to those in a study by Li et al. (2017a) which also considered variable ejector loss coefficients. Furthermore, Fig. 4 shows a comparison of present study results with experimental results from Huang and Chang (1999) for an ejector using R141b. As illustrated, very good agreement is evident for the entrainment ratio in all modes of operation and for the condensing temperatures at the critical point. With R245fa as the working fluid, the entrainment ratio results are within $\pm 5.34 \%$, the cooling capacity is within $\pm 4.84 \%$ and the COP is within $\pm 4.53 \%$ of the experimental results in Shestopalov et al. (2015). Table 3 also presented in Mwesigye and Dworkin (2018) shows the ability of the developed model to determine performance with R365mfc (Wang et al., 2009). With R365mfc, the model predicts the COP within $\pm 11 \%$ and the cooling capacity is within $\pm 9 \%$, respectively. Overall, the developed model was shown to give better prediction of performance for dry and isentropic working fluids. 


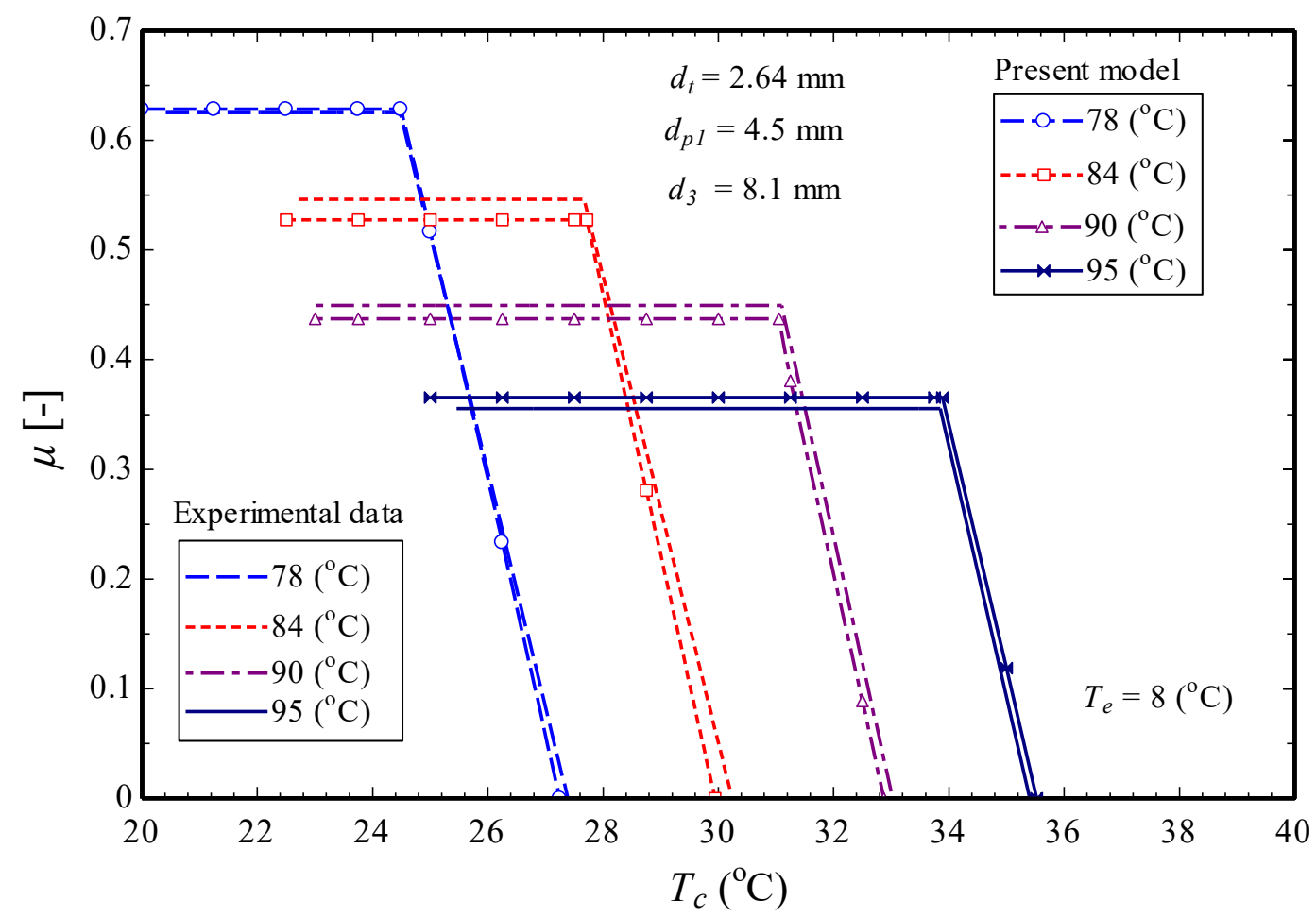

Fig. 4. Validation of ejector performance at different generator temperatures and $T_{e}=8{ }^{\circ} \mathrm{C}$ with R141b (Huang and Chang, 1999)

Table 3: Validation of the combined model using experimental data for R365mfc (Wang et al., 2009)

\begin{tabular}{|c|c|c|c|c|c|c|c|}
\hline \multicolumn{8}{|c|}{$T_{g}=90^{\circ} \mathrm{C}, A_{r}=7.73$} \\
\hline & \multicolumn{3}{|c|}{ COP } & \multicolumn{4}{|c|}{ Cooling Capacity $\dot{Q}_{e}(\mathrm{~kW})$} \\
\hline$T_{e}\left({ }^{\circ} \mathrm{C}\right)$ & $\begin{array}{l}\text { (Wang et } \\
\text { al., 2009) }\end{array}$ & $\begin{array}{r}\text { Present } \\
\text { study }\end{array}$ & Error, $\%$ & $T_{e}\left({ }^{\circ} \mathrm{C}\right)$ & $\begin{array}{l}\text { (Wang et } \\
\text { al., 2009) }\end{array}$ & $\begin{array}{r}\text { Present } \\
\text { study }\end{array}$ & Error, $\%$ \\
\hline 10.58 & 0.1295 & 0.1440 & 10.89 & 10.42 & 0.375 & 0.390 & 4.05 \\
\hline 11.70 & 0.1459 & 0.1609 & 10.31 & 11.80 & 0.436 & 0.430 & -1.45 \\
\hline 16.11 & 0.2197 & 0.2298 & 4.61 & 15.93 & 0.629 & 0.611 & -2.79 \\
\hline 20.72 & 0.2880 & 0.3194 & 10.90 & 20.64 & 0.844 & 0.843 & -0.10 \\
\hline \multicolumn{8}{|c|}{$T_{g}=90^{\circ} \mathrm{C}, A_{r}=9.10$} \\
\hline 9.14 & 0.2197 & 0.1943 & -11.36 & 9.16 & 0.690 & 0.631 & -8.52 \\
\hline 10.99 & 0.2443 & 0.2171 & -11.12 & 10.88 & 0.759 & 0.729 & -3.99 \\
\hline 15.91 & 0.3017 & 0.3110 & 3.09 & 15.70 & 0.959 & 1.024 & 6.75 \\
\hline 18.67 & 0.3372 & 0.3741 & 10.94 & 18.57 & 1.082 & 1.182 & 9.22 \\
\hline
\end{tabular}




\subsection{Results and discussion}

Although results for all the considered ejectors have been used in the derivation of correlations for optimal COP and optimal generator temperatures, to present results concisely, only ejectors AA, 3, 4, AC, 1 and $\mathrm{EH}$ with area ratios of 6.44, 7.04, 7.51, 8.28, 9.13 and 10.64, respectively, have been used to generate figures for the detailed discussion in the succeeding sections. Moreover, it has been shown that in the critical mode of operation, the critical COP is shown to increase as the area ratio increases regardless of the ejector geometry as shown in Fig. 5(a). Whereas the critical condensing temperature is shown to reduce as the area ratio increases as depicted in Fig. 5 (b). Similar trends are obtainable at other ejector area ratios for each considered parameter as has been illustrated in Figure 5 for the critical COP and critical condensing temperature.

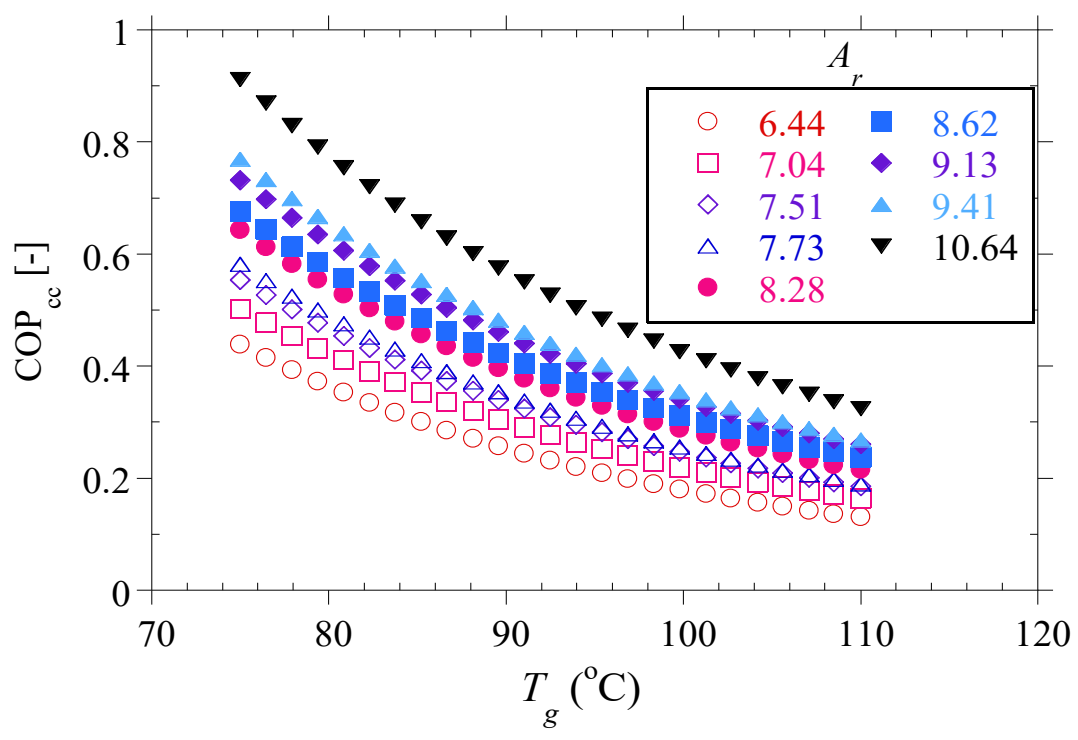




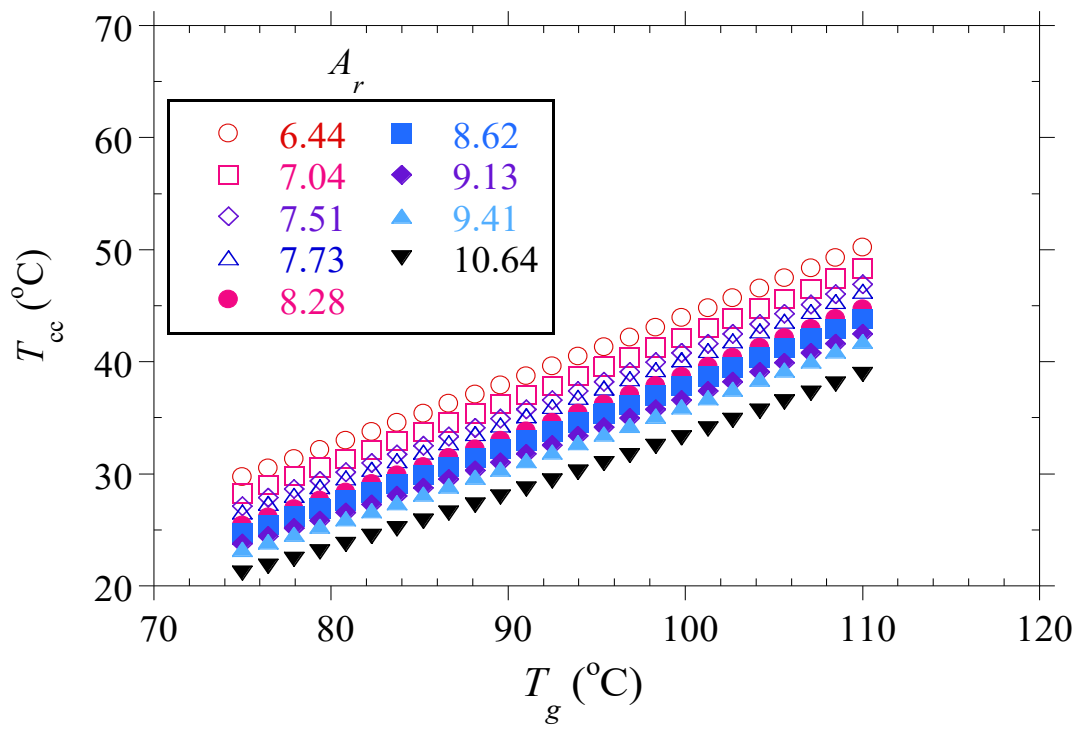

Fig. 5. Performance in the critical mode of operation (a) critical COP at the different area ratios in Table 2 for $T_{e}=12{ }^{\circ} \mathrm{C}$, and (b) critical condensing temperature

Figure 6(a) depicts the COP as a function of the condensing temperature at different evaporator temperatures for a generator temperature of $70^{\circ} \mathrm{C}$ with an area ratio of 8.28. At this area ratio and for generator temperatures equal to or lower than $70^{\circ} \mathrm{C}$, the ejector operates only in the subcritical mode when the evaporator temperatures are below $4{ }^{\circ} \mathrm{C}$. The temperature range under which the ejector operates in the critical mode of operation depends on the ejector design, evaporator temperatures and generator temperatures. At a given generator temperature, increasing the evaporator temperature increases the range of condensing temperatures under which the system operates in the critical mode as well as the ejector breakdown temperature. Moreover, as the generator temperature increases, there is a wide range of condensing temperatures over which the ejector works in the critical mode of operation, but the $\mathrm{COP}$ at the critical point diminishes. This can be seen in Fig. 6(b) at $A_{r}=8.28$ with $T_{g}=100{ }^{\circ} \mathrm{C}$. The critical temperature is between $31{ }^{\circ} \mathrm{C}$ and $35^{\circ} \mathrm{C}$ compared to between $21^{\circ} \mathrm{C}$ and $25^{\circ} \mathrm{C}$ in Fig. $6\left(\right.$ a) at the same area ratio with $T_{g}=70{ }^{\circ} \mathrm{C}$, but the critical COP reduces. As an example, at $T_{e}=12^{\circ} \mathrm{C}$ and $A_{r}=8.28$, the critical COP declines from 0.76 to 0.39 as the generator temperature changes from $70^{\circ} \mathrm{C}$ to $100{ }^{\circ} \mathrm{C}$. 


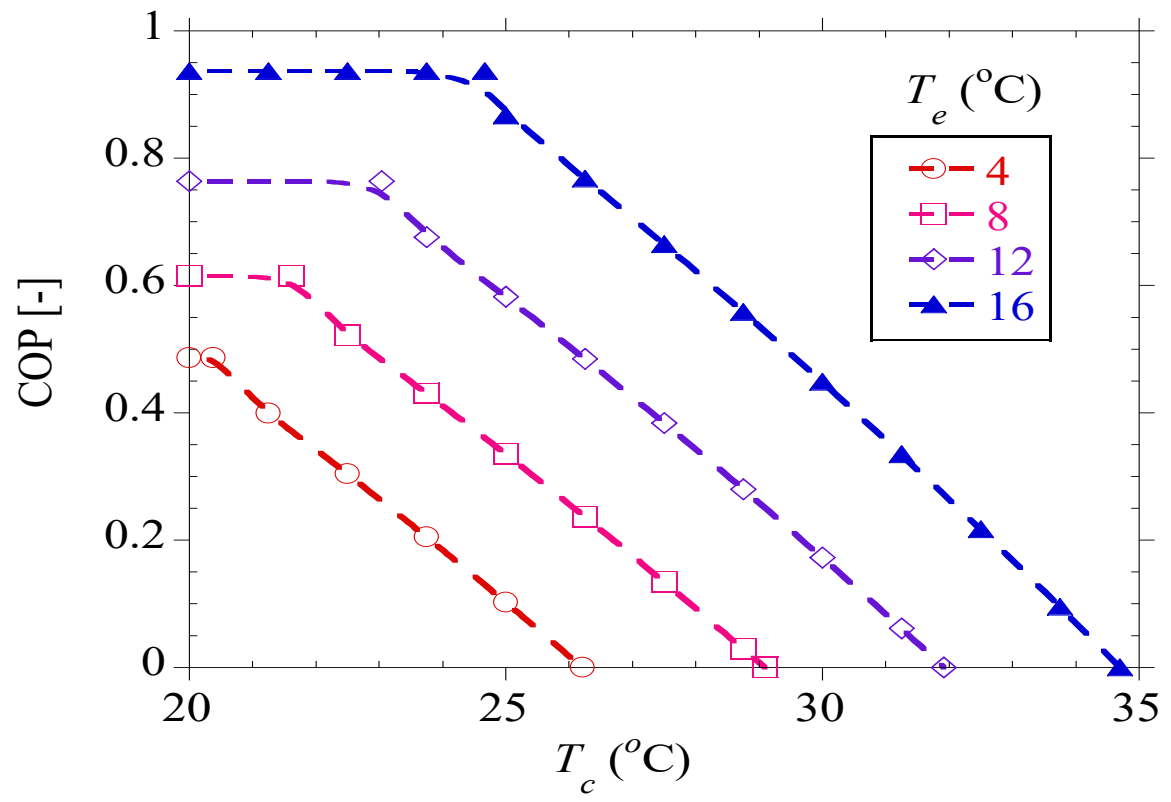

(a)

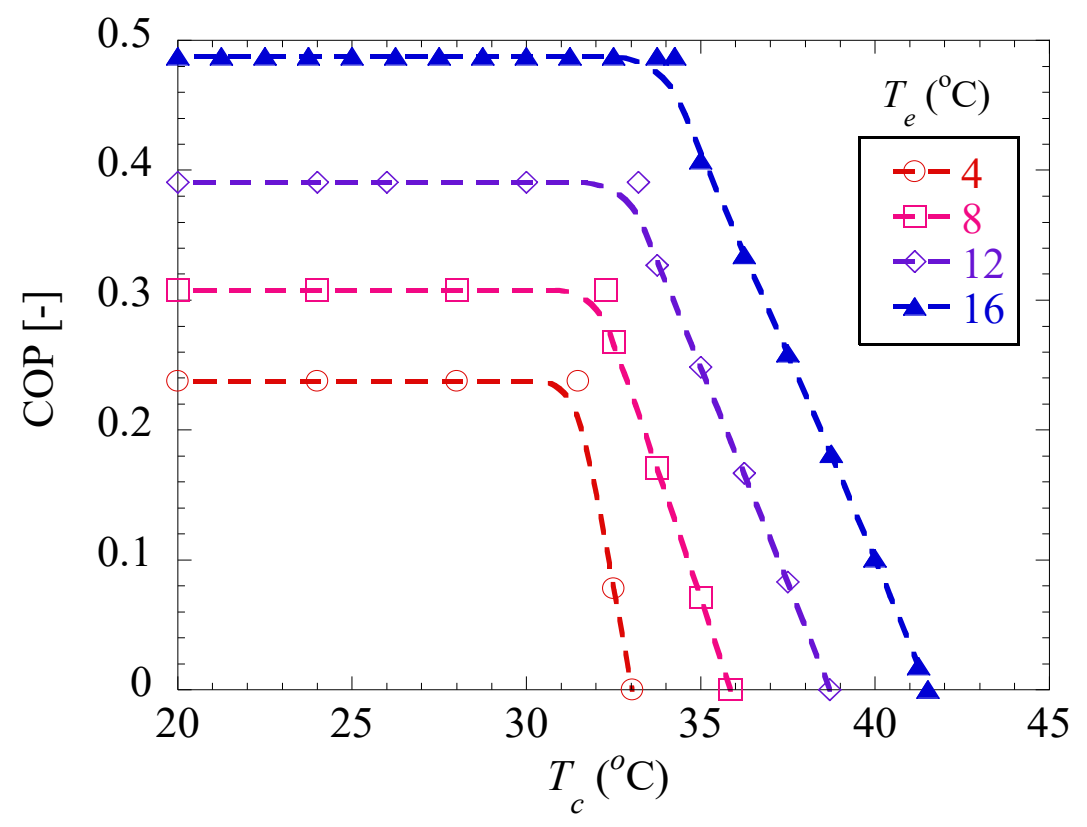

(b) 


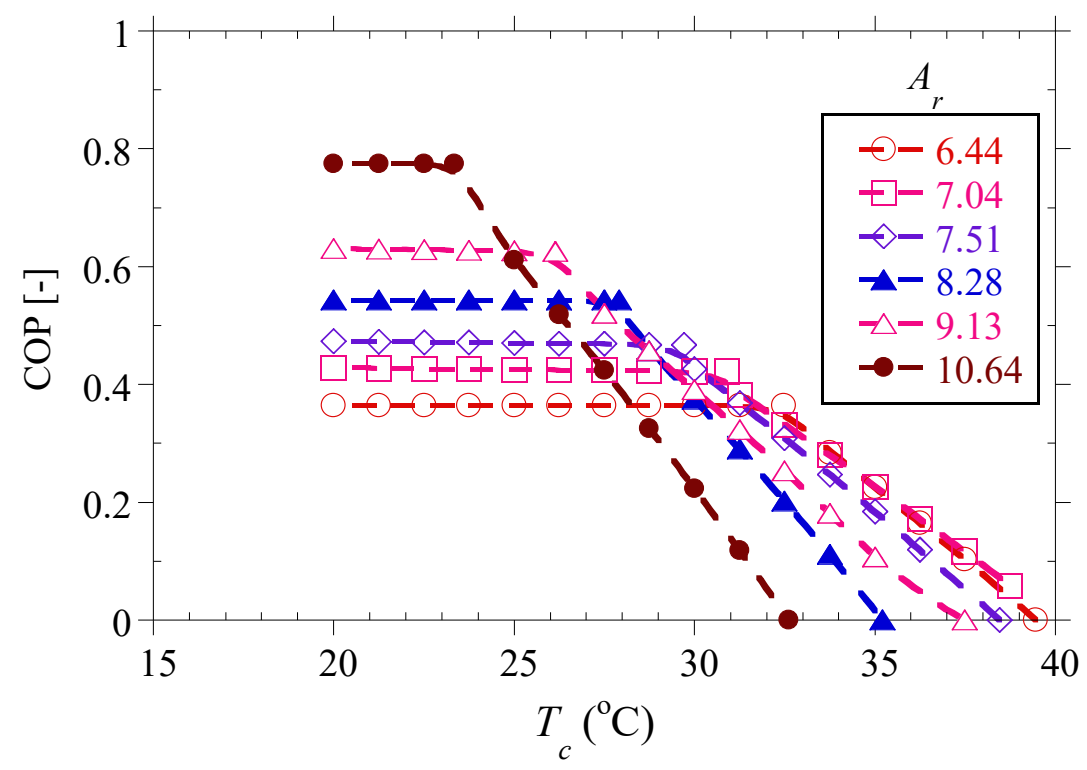

(c)

Fig. 6. $\mathrm{COP}$ as a function of condensing temperature (a) at different evaporator temperatures with $A_{r}=8.28$ and $T_{g}=70^{\circ} \mathrm{C}$ (b) a) at different evaporator temperatures with $A_{r}=8.28$ and $T_{g}=$ $100{ }^{\circ} \mathrm{C}$, and (c) at different area ratios with $T_{e}=12{ }^{\circ} \mathrm{C}$ and $T_{g}=80^{\circ} \mathrm{C}$

When the generator temperatures are low, the suction conditions created in the ejector will not be significant enough to entrain a substantial amount of the secondary fluid from the evaporator. As such, the operation in the subcritical mode at lower evaporator temperatures is mainly due to the less secondary flow that will be entrained at such low pressures, leaving only the primary flow choked. The ejector breakdown temperature; the temperature at which the ejector malfunctions also increases with rising generator temperatures. As indicated, higher COPs are achievable at higher evaporator temperatures and lower generator temperatures. However, it is essential that the critical temperature is higher than the prevailing temperature where the condenser must reject the heat. In practice, the environment in which the ejector operates dictates the generator temperature for a given ejector geometry. Higher generator temperatures and lower area ratios ensure higher critical condensing and ejector breakdown temperatures but with low COPs. In this study, generator temperatures lower than $70^{\circ} \mathrm{C}$ require ambient temperatures lower than $35^{\circ} \mathrm{C}$ depending on the evaporator temperature for the ejector to function, but the critical temperatures for efficient operation are lower than $25^{\circ} \mathrm{C}$ at the considered evaporator temperatures. A generator temperature of $100{ }^{\circ} \mathrm{C}$ will work for condensing temperatures up to $42{ }^{\circ} \mathrm{C}$, with critical temperatures ranging 
between $30^{\circ} \mathrm{C}$ and $35^{\circ} \mathrm{C}$ for evaporator temperatures between $4{ }^{\circ} \mathrm{C}$ and $16{ }^{\circ} \mathrm{C}$ for the considered area ratios.

The performance of the ejector system at different condensing temperatures with different area ratios is shown in Fig. 6(c) when the evaporator temperature is $12^{\circ} \mathrm{C}$ and the generator temperature is $80^{\circ} \mathrm{C}$. The figure shows that at these conditions, the ejector works in both the critical and sub critical modes depending on the condensing temperature. The critical point is shown to increase with reducing area ratios for the fixed generator and evaporator temperatures. Thus, lower area ratios give a wide range of condensing temperatures under which the ejector works in the critical mode, but, the COP under the critical mode of operation reduces as the area ratio diminishes. At a given generator temperature, the primary fluid flow rate is fixed and thus the suction conditions will depend on the area ratio of the ejector. For smaller area ratios, the primary flow and secondary flow remain choked over a wide range of condensing temperatures while for larger area ratios, the suction capacity is not sufficient to ensure that both the primary flow and secondary flow stay choked simultaneously. Increasing the generator temperature will extend the range of condensing temperature for which both fluids are choked simultaneously. As such, a combination of higher area ratios and generator temperatures can be used to ensure that the ejector operates with better $\mathrm{COP}$ values and the desired condensing temperatures.

When the area ratio is kept constant and the generator temperature is varied, the critical condensing temperature is shown to increase as the generator temperature rises as indicated in Figs. 7 (a) and (b). This is mainly because, a higher generator temperature provides an increased pressure for the primary flow into the ejector nozzle and therefore improves its suction capacity as well as its ability overcome greater back pressures. As the generator temperature reduces, the available pressure is not high enough to overcome the increasing back pressure and therefore gives rise to lower values of the critical condensing temperature. As the figures show, for rejection of heat to reasonable ambient temperatures and to obtain better performance values, a generator temperature of $90{ }^{\circ} \mathrm{C}$ seems sufficient for evaporator temperatures above $8^{\circ} \mathrm{C}$ and area ratios lower than 9.41. At this temperature, the ejector works in the critical mode of operation up to $40{ }^{\circ} \mathrm{C}$ after which increasing the condensing temperature leads to operation in the subcritical mode and eventual breakdown at $43{ }^{\circ} \mathrm{C}$ when $T_{e}=12^{\circ} \mathrm{C}$ and $A_{r}=6.44$ as shown in Fig 7(a). The COP in the critical mode with $A_{r}=$ 6.44 and $T_{g}=90{ }^{\circ} \mathrm{C}$ is 0.25 compared to 0.53 at $70{ }^{\circ} \mathrm{C}$ which has a critical temperature of $27{ }^{\circ} \mathrm{C}$ and a breakdown temperature of $36^{\circ} \mathrm{C}$. 


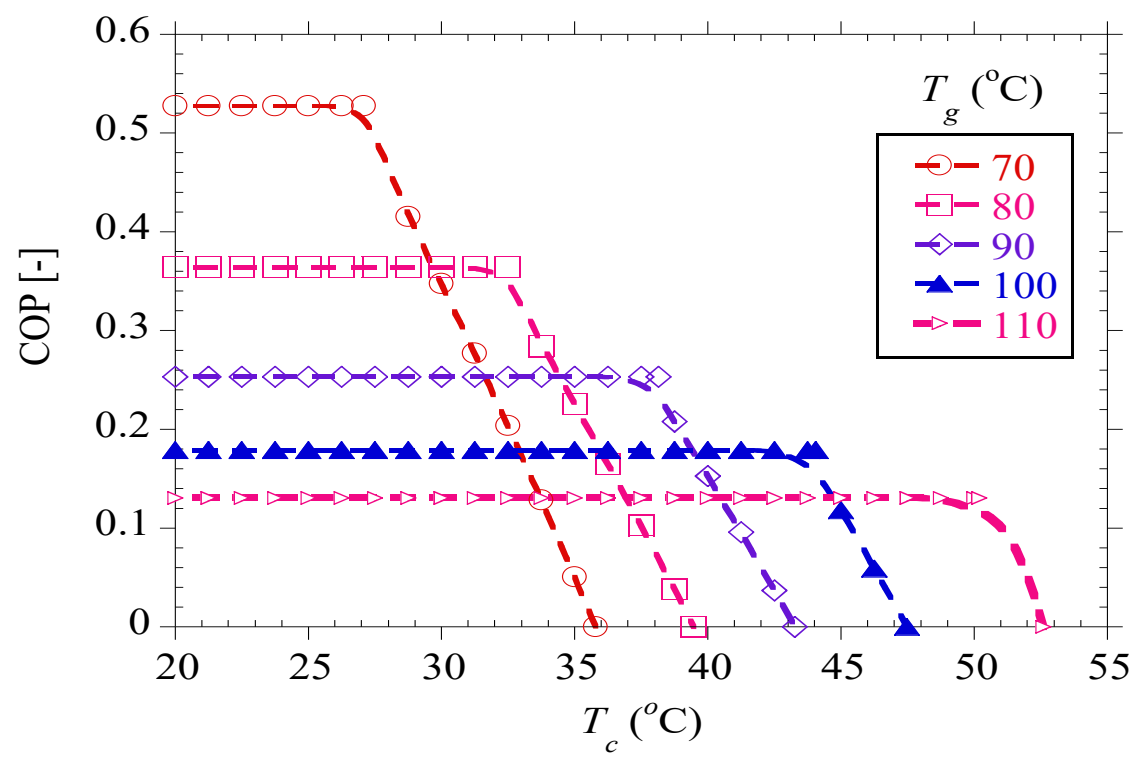

(a)

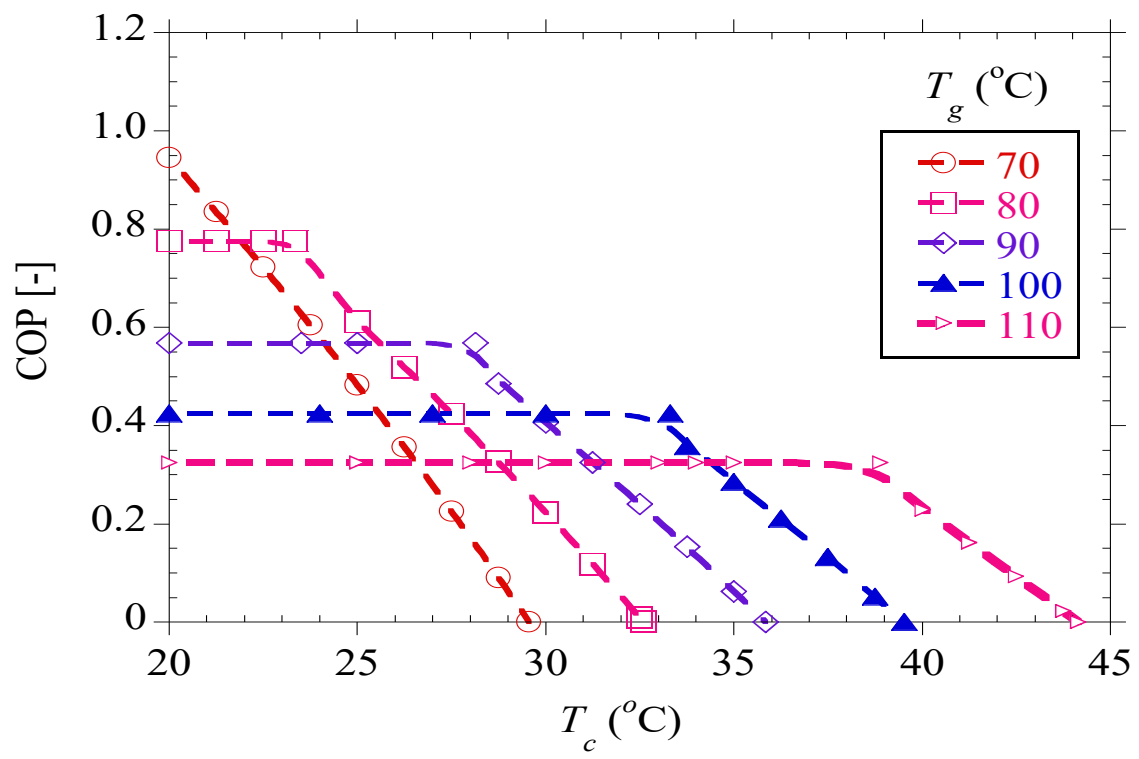

(b)

Fig. 7. $\mathrm{COP}$ as a function of condensing temperature at different generator temperatures with

$$
T_{e}=12{ }^{\circ} \mathrm{C} \text { (a) } A_{r}=6.44 \text { and, (b) } A_{r}=10.64
$$

Figure 7 also shows that in the critical mode operation, increasing the area ratio gives higher COPs, but lowers the critical condensing temperatures. As Fig. 7(a) indicates, for an area ratio of 6.44, and a generator temperature of $110{ }^{\circ} \mathrm{C}$, the critical COP is 0.13 and the critical condensing temperature is $50^{\circ} \mathrm{C}$. As the area ratio increases to 10.64 for the same conditions, the critical COP is around 0.32 and critical condensing temperature reduces to $40^{\circ} \mathrm{C}$ as shown in Fig. $7($ b). With this, higher generator temperatures are required for the ejector system to operate in the critical 
mode over an extended range of condensing temperatures as area ratios increase. With increased generator temperatures, a wide range of condensing temperatures under which the ejector works in the critical mode can be achieved.

In the critical mode of operation, the performance of the ejector is at its best and does not change as the condenser temperature increases. As such, it is desirable to operate the ejector system in the critical mode of operation as much as possible. The variation of the COP in the critical mode of operation with generator temperature at different evaporator temperatures and different area ratios is displayed in Figs. 8 (a) and (b), respectively.

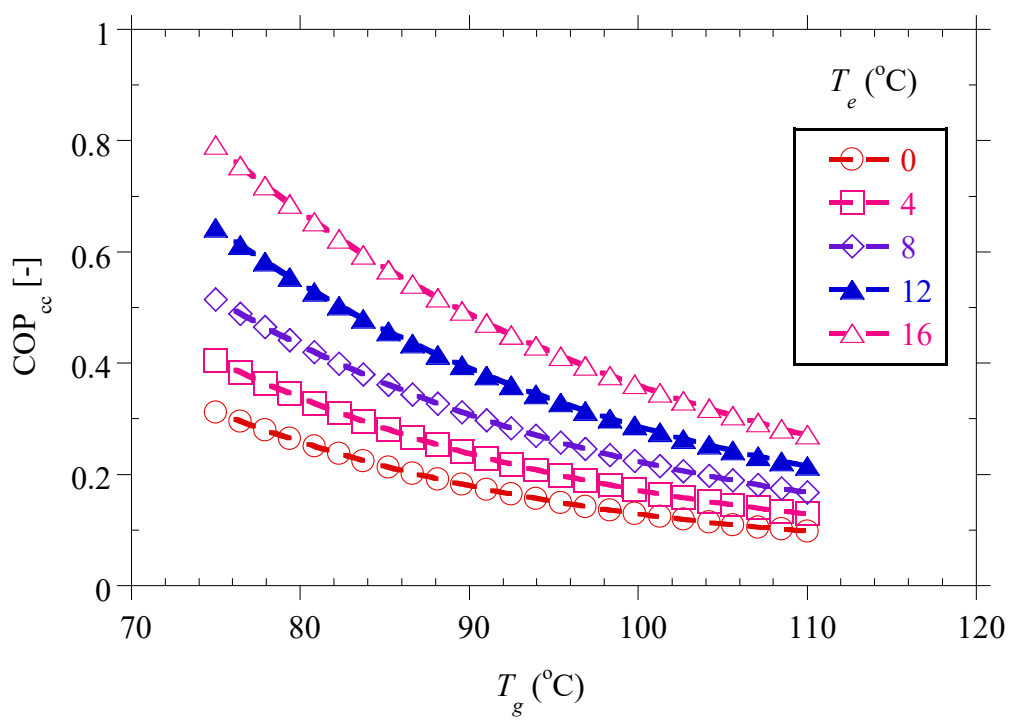

(a)

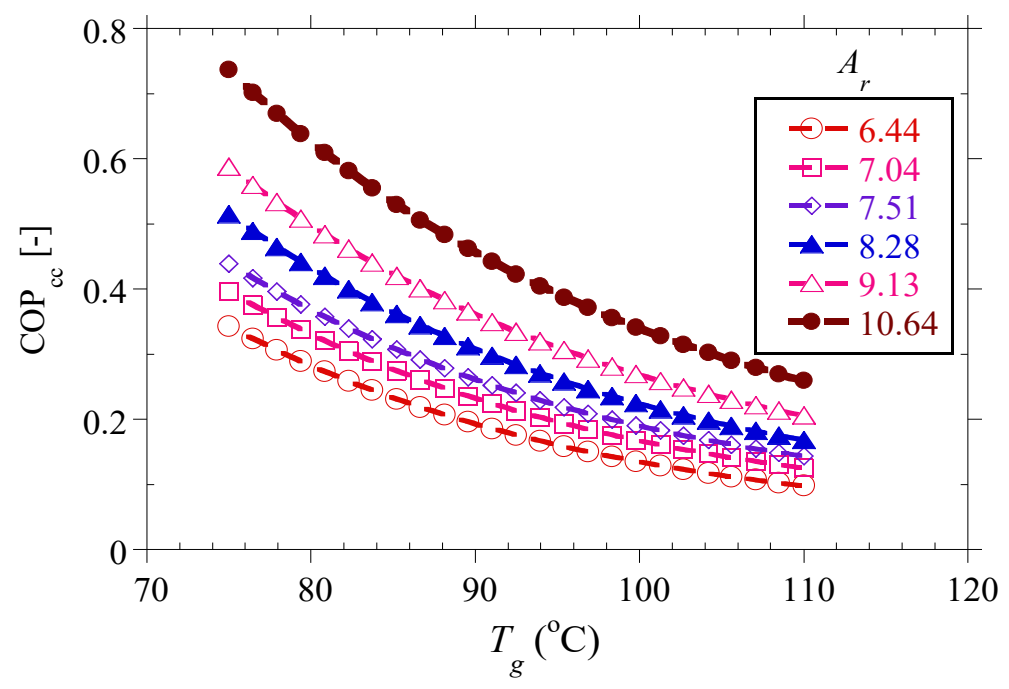

(b)

Fig. 8. Critical COP as a function of generator temperature (a) at different evaporator temperatures with $A_{r}=8.28$, and (b) different area ratios with $T_{e}=8{ }^{\circ} \mathrm{C}$ 
As Fig. 8(a) illustrates, the COP in the critical mode of operation decreases as the generator temperature increases and as the evaporator temperature reduces. The same trend of decreasing performance as the generator temperatures increase was shown in studies by Tashtoush et al. (2015) and Chen et al. (2017). Higher generator temperatures result in increasing primary flow rates expanding in the ejector nozzle thereby choking the diffuser throat and reducing the suction capacity of the ejector. Higher evaporator temperatures at a given generator temperature result in better COPs. The ease with which the secondary flow is entrained at high evaporator temperatures is the major reason for improved performance. At a given generator temperature, increasing the evaporator temperature lowers the ejector pressure lift thereby increasing the secondary flow rate further improving performance of the system.

Figure 8(b) depicts clearly the influence of the area ratio on ejector performance at $T_{e}=8{ }^{\circ} \mathrm{C}$. At a given generator temperature, the performance improves as the area ratio increases. Even though low generator temperatures show better performance, it has been shown that the critical condensing temperature declines as generator temperatures decrease. For an ejector exchanging heat with the ambient, the condensing temperature needs to be more than $5{ }^{\circ} \mathrm{C}$ above the ambient temperature for effective heat transfer from the condenser to the surroundings. Thus, in air conditioning applications and for cooling purposes, condensing temperatures above $35{ }^{\circ} \mathrm{C}$ will be common depending on the location where the system will be used.

The cooling capacity at the critical point follows the same trend as the COP. As Figs. 9 (a) and (b) depict, the cooling capacity declines as the generator temperature rises as was the case for COP. The cooling capacity reduces as the generator temperatures increase and as the area ratios decrease for the same reasons already discussed for the COP. Even though lower generator temperatures show better performance, they give lower critical condensing temperatures, which might not be practical when cooling is most needed. For applications requiring lower evaporator temperatures 


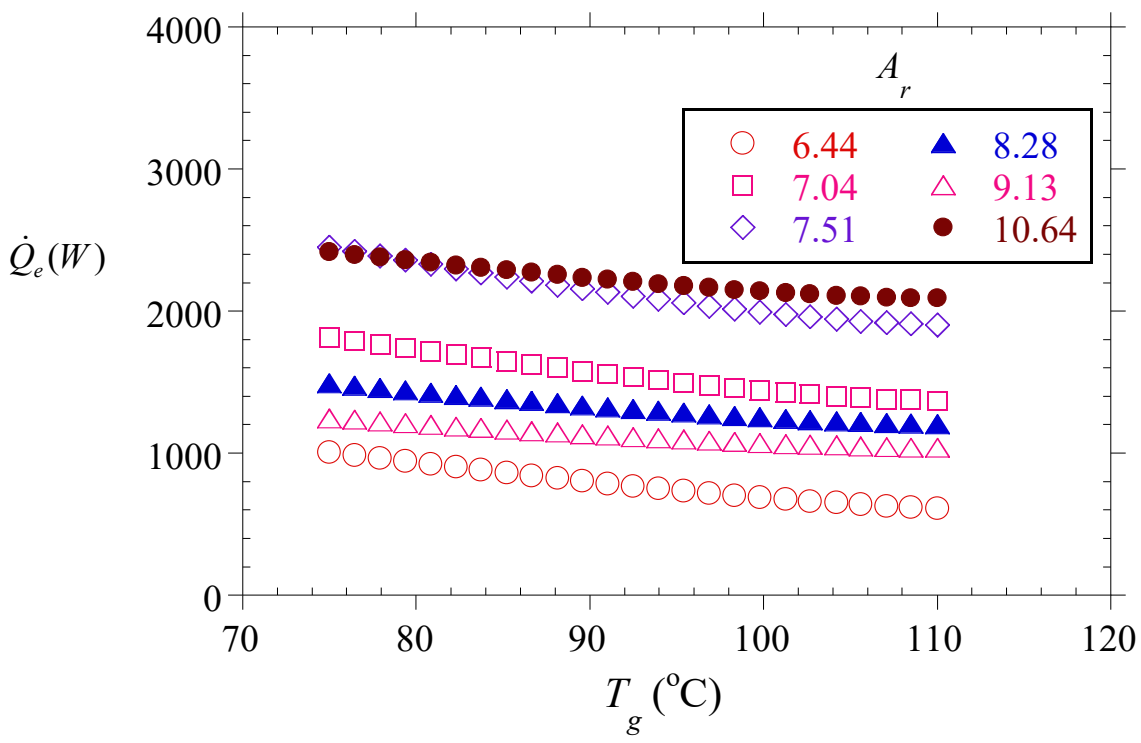

(a)

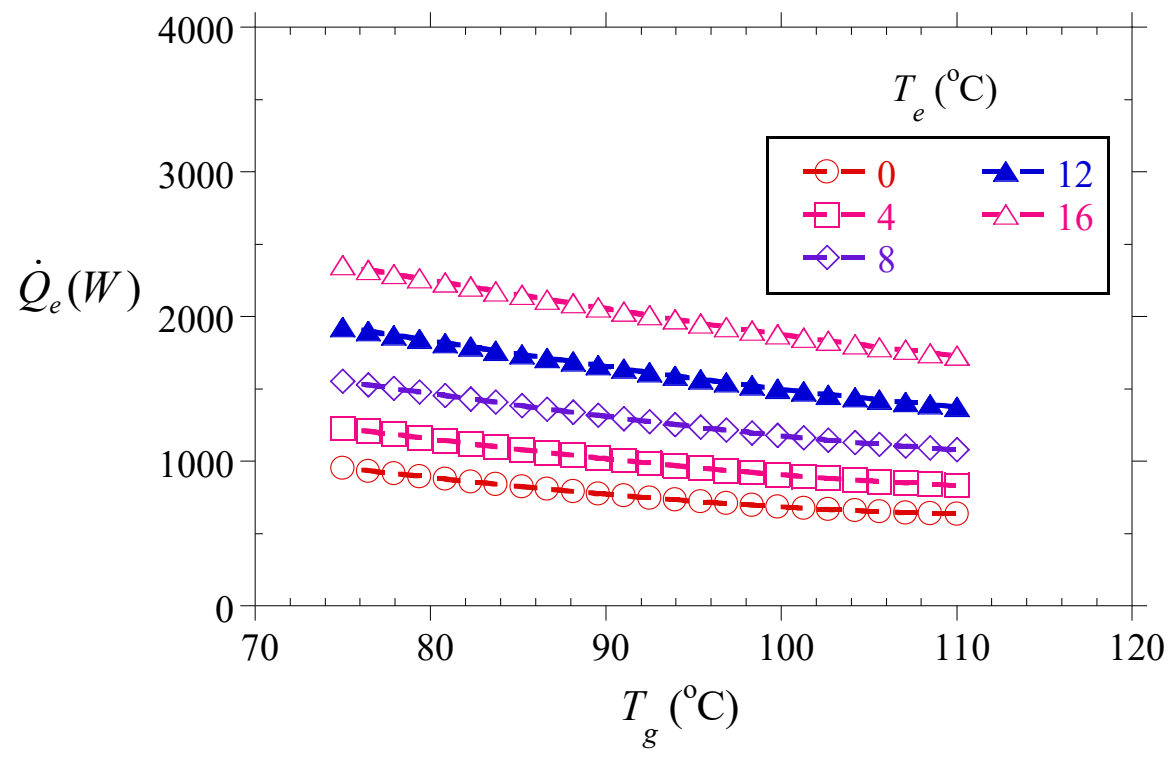

(b)

Fig. 9. Cooling capacity in the critical mode as a function of generator temperature (a) at different area ratios with $T_{e}=8{ }^{\circ} \mathrm{C}$, and (b) at different evaporator temperatures with $A_{r}=8.28$.

and where condensing can be provided with lower temperatures, the ejector refrigeration system guarantees better COPs and significant cooling loads. 


\subsection{Ejector performance optimization}

A consideration of the energy balances across the system components indicates optimum operating conditions for given combinations of evaporator temperature, area ratio and condensing temperature. Figs.10 (a) and (b) depict the COP as a function of generator temperature using the performance curve proposed in Mwesigye and Dworkin (2018). In determining these curves, the area ratio and the evaporator temperature are kept constant while the generator temperature is varied for a given condenser temperature. The determination of the critical condensing temperature, then permits one to identify whether the ejector is working in the critical or subcritical mode. Once the mode of operation has been established, the appropriate values of the COP are recorded and the figures such as Fig. 10 (a) and (b) plotted. As illustrated, there is a generator temperature that gives the optimum performance for a fixed area ratio and evaporator temperature.

For small area ratios and low condensing temperatures, the optimal generator temperatures are much lower. For example, at $A_{r}=6.44$ and $T_{e}=4^{\circ} \mathrm{C}$, the optimal generator temperature is lower than $70^{\circ} \mathrm{C}$. The optimal generator temperature rises as the condensing temperature increases. It should also be noted that at a given condensing temperature and for the considered area ratio and evaporator temperature, the ejector works in the subcritical mode when temperatures are less than the optimal generator temperature, and in the critical mode for temperatures greater than the optimal generator temperature. This is the reason why the COP follows the same curve after the optimum generator temperature as the condensing temperature increases. This is because the COP at condensing temperatures lower than the critical condensing temperature remains the same as previously indicated in Figs. (6) and (7). At higher evaporator temperatures, the trend remains the same (Fig. 10(b)), but the COP is greater than that at lower evaporator temperatures as expected.

The optimal generator temperatures are also clearly indicated on a graph of the COP as a function of generator temperature at different evaporator temperatures as shown in Fig. 10(c). The optimum $\mathrm{COP}$ increases with rising evaporator temperatures. This is expected since the secondary flow is easily entrained at higher evaporator pressures. There is a slight rise in the optimal generator temperature as the evaporator temperature reduces. At low evaporator temperatures, a higher generator temperature would be required to create the necessary vacuum to entrain the secondary flow. Same trends are obtained at other area ratios. However, the optimum generator temperature increases as the area ratio rises. As the area ratio increases, higher primary fluid flow rates are 
needed to keep both the primary flow and secondary flows choked and maintain the ejector in the critical mode of operation. Thus, optimal performance occurs at greater generator temperatures as the area ratio increases.

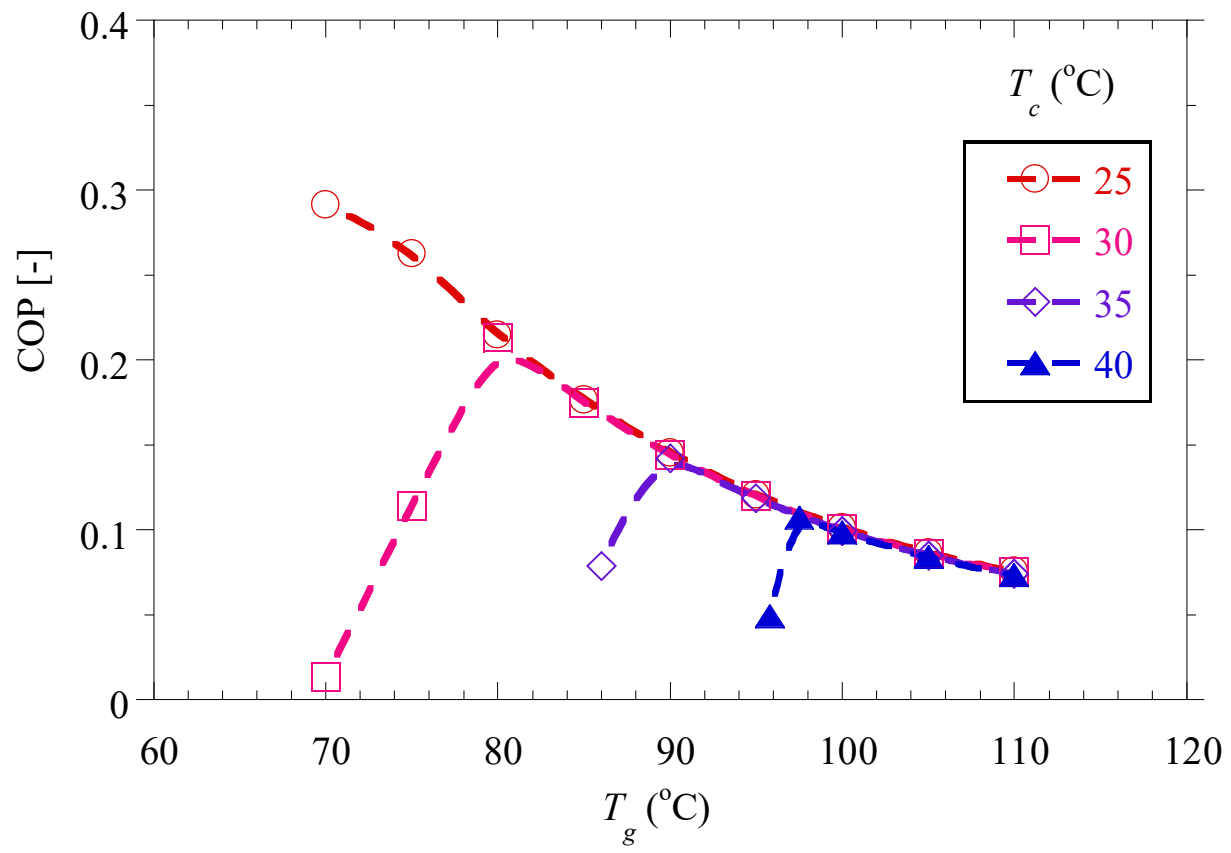

(a)

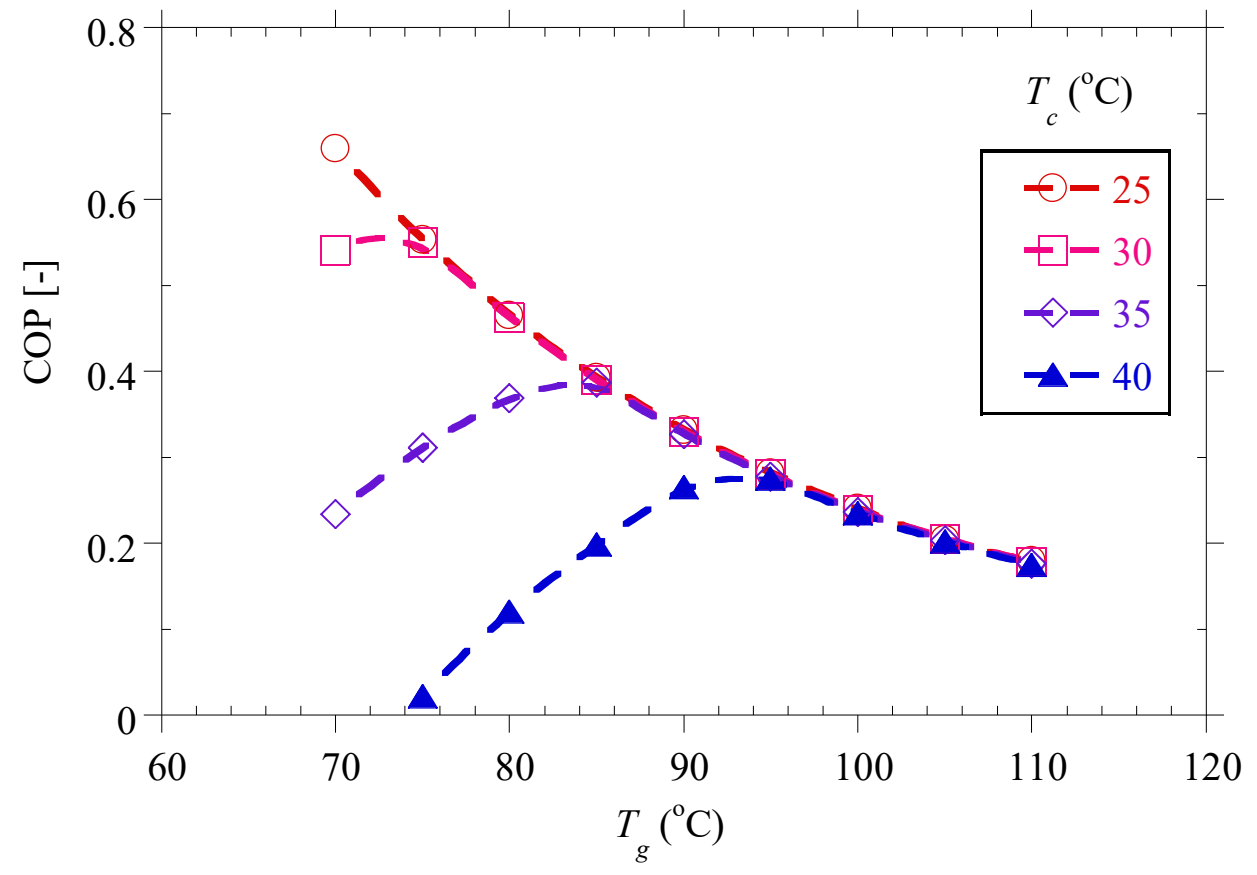

(b) 


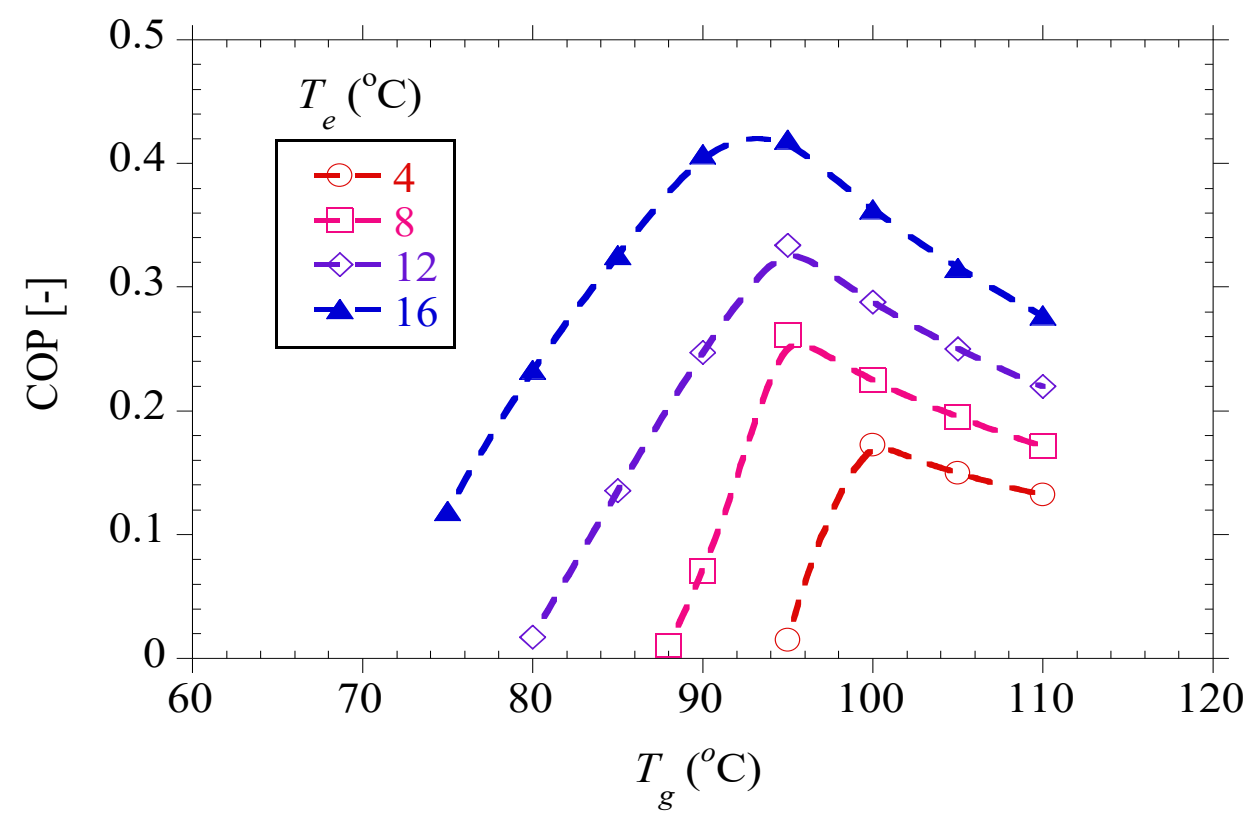

(c)

Fig. 10. Variation of the COP with generator temperature (a) at different condensing temperatures for (a) $A_{r}=6.44$ and $T_{e}=4{ }^{\circ} \mathrm{C}$, and (b) at different condensing temperatures for $A_{r}=6.44$ and $T_{e}=16^{\circ} \mathrm{C}$, and (c) at different evaporator temperatures for $A_{r}=8.24$ and

$$
T_{c}=35^{\circ} \mathrm{C}
$$

Extracting the data at the optimal operating conditions, graphs such as Figs. 11 (a)-(c) that show the optimal ejector performance can be obtained, enabling the designer to size the systems accordingly. Fig.11 (a) shows the dependence of the optimal COP on the condensing temperature at different evaporator temperatures with $A_{r}=6.44$. At an evaporator temperature of $8{ }^{\circ} \mathrm{C}$, the optimal COP varies between 0.28 and 0.16 for condensing temperatures between $30{ }^{\circ} \mathrm{C}$ and $40{ }^{\circ} \mathrm{C}$ for $A_{r}=6.44$. The greater the evaporating temperature, the higher the optimal COP. The optimal $\mathrm{COP}$ is between 0.57 and 0.27 at an evaporator temperature of $16^{\circ} \mathrm{C}$ when the area ratio is 6.44 . As earlier discussed, ejector performance improves with increasing evaporator temperatures. Therefore, where convenient, refrigeration/air conditioning should be provided at high evaporating temperatures to obtain the benefits of improved performance. The same trend exists at the different area ratios considered, with increasing area ratios giving higher optimal COPs. It should be noted that greater optimal COPs are obtained at the expense of increased heat input since the optimal generator temperature was shown to increase at higher area ratios. 
Figure 11(b) shows the generator temperatures that give maximum performance at different area ratios when the evaporator temperature is $8{ }^{\circ} \mathrm{C}$. As the figure indicates, the required optimal generator temperature is greater with increasing condensing temperatures and area ratios. As the condensing temperature and area ratio increase, significantly higher primary flow pressures are needed to ensure better suction capacity, for the ejector to give its best performance. This is achieved by increasing the energy transfer by heat to the generator and therefore providing a higher temperature and pressure stream to the nozzle. The optimal generator temperature at the lowest area ratio is below $70{ }^{\circ} \mathrm{C}$ at a condensing temperature of $25^{\circ} \mathrm{C}$ and is more than $110{ }^{\circ} \mathrm{C}$ at the largest area ratio with a condensing temperature of $40^{\circ} \mathrm{C}$. As the evaporator temperature increases, there is a slight reduction in the optimal generator temperature at a given condensing temperature as less primary flow velocity is needed to entrain the secondary flow. The trend is the same at other values of the evaporator temperatures considered.

Figure 11 (c) shows the optimal cooling capacity as a function of condensing temperature at the ejector area ratios considered in this study. Like the COP, it generally reduces as the condensing temperatures rise. At lower area ratios, the optimal generator temperature is less than $70{ }^{\circ} \mathrm{C}$ for condensing temperatures below $25{ }^{\circ} \mathrm{C}$. As the area ratios increase, the optimal generator temperature becomes more than $110^{\circ} \mathrm{C}$ at condensing temperatures of $40{ }^{\circ} \mathrm{C}$ and above. For these reasons, the lines at $A_{r}=6.44$ and $A_{r}=10.64$ are shorter than the rest. As such, lower condensing temperatures will require less heat input while higher condensing temperatures will need increased generator temperatures.

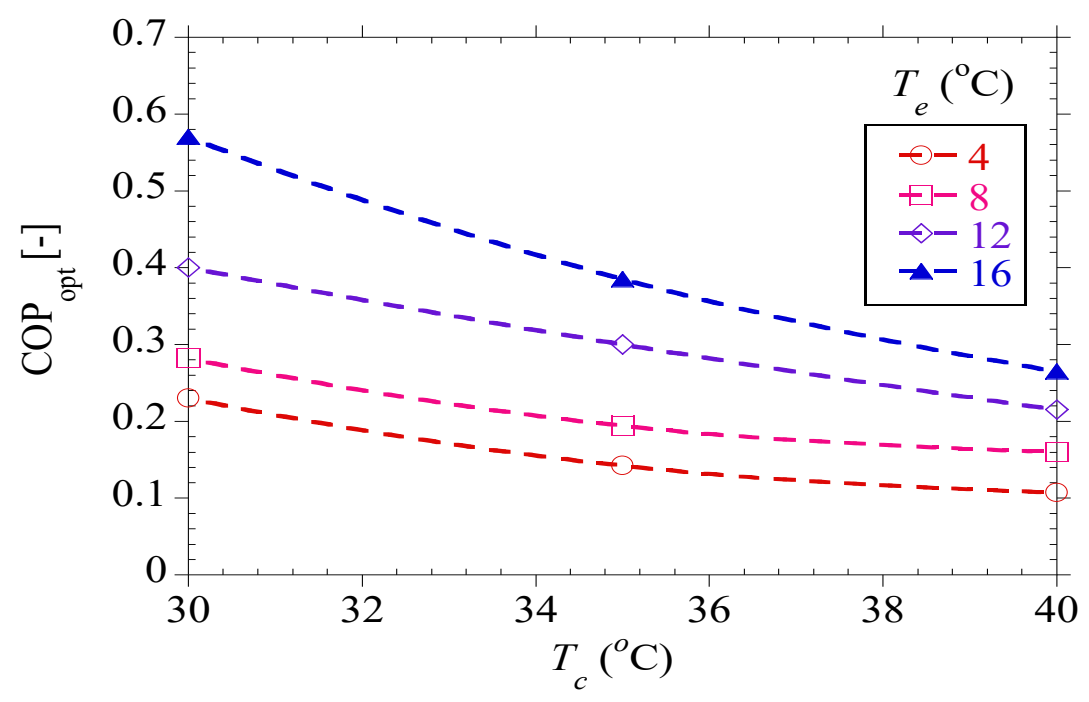




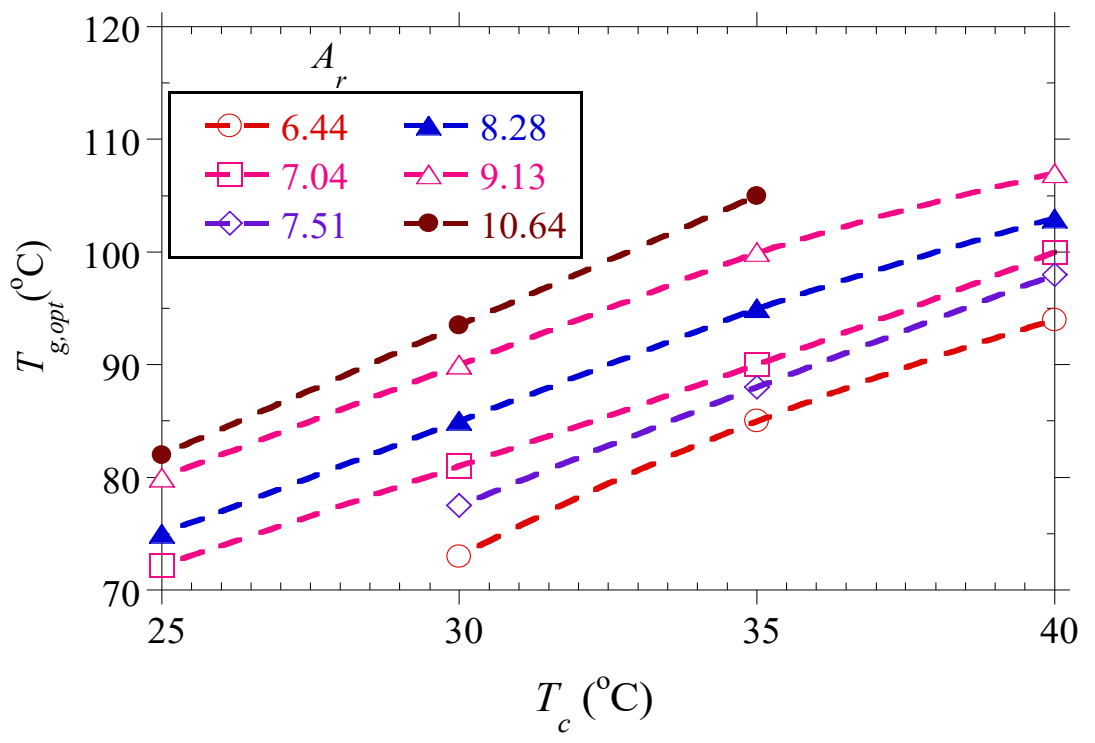

(b)

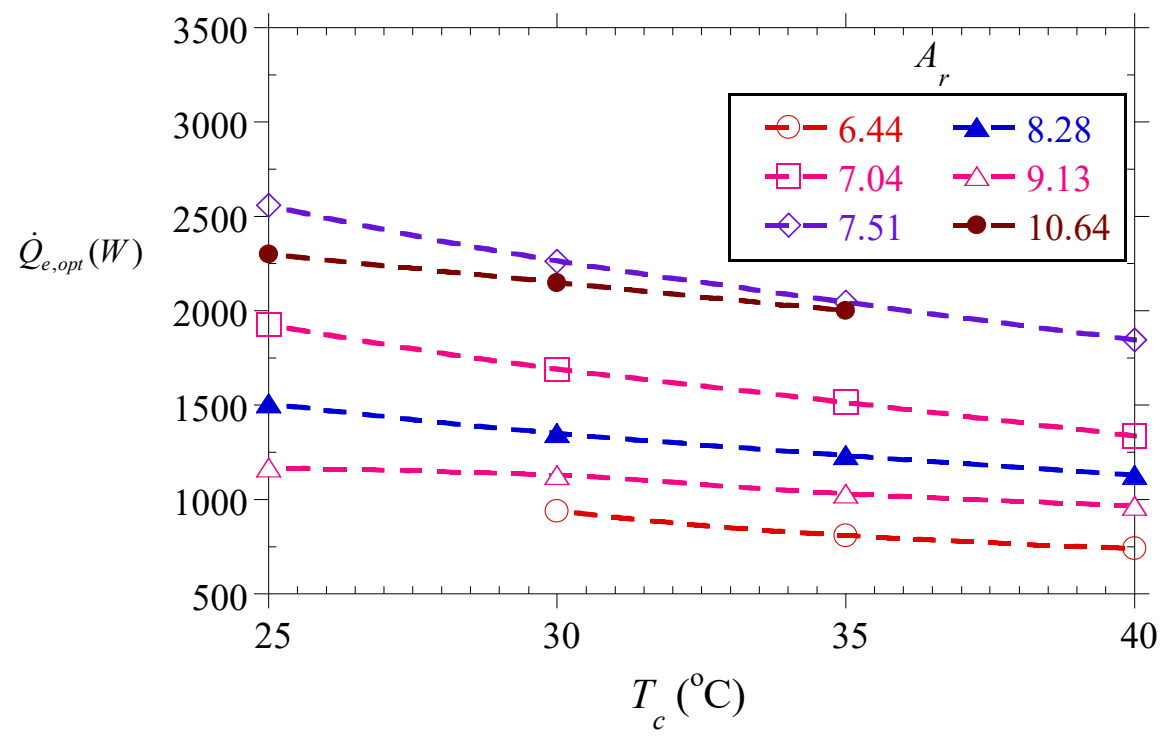

(c)

Fig. 11. Optimal performance with different condensing temperatures (a) optimal COP at different evaporator temperatures for $A_{r}=6.44$, (b) optimal generator temperature at different area ratios with $T_{e}=8{ }^{\circ} \mathrm{C}$, and (c) optimal cooling capacity at different area ratios with $T_{e}=8^{\circ} \mathrm{C}$

Correlations for the optimal generator temperature and optimal COP have been derived. For the range of condensing temperatures $30-40{ }^{\circ} \mathrm{C}$, the optimal generator temperature in ${ }^{\circ} \mathrm{C}$ can be estimated using the correlation

$$
T_{g, o p t}=20.887 A_{r}^{0.3804}\left(\tilde{T}_{e}\right)^{-1.4223}\left(\tilde{T}_{c}\right)^{6.3111}
$$


Where $\tilde{T}_{e}=T_{e} / 273.15$ and $\tilde{T}_{c}=T_{c} / 273.15$ (with $T_{e}$ and $T_{c}$ in $\mathrm{K}$ ) and the correlation is valid for the range of parameters considered in this study i.e. $6.44 \leq A_{r} \leq 10.64,30 \leq T_{c} \leq 40{ }^{\circ} \mathrm{C}$, and $4 \leq T_{e}$ $\leq 16^{\circ} \mathrm{C}$. The $\mathrm{R}^{2}$ value for the non-linear regression analysis was $97.56 \%$ for the resulting 96 observations of the optimal generator temperature. The number of iterations to minimise the error were 24 with a convergence tolerance factor of $10^{-10}$.

The COP at the optimal generator temperature is obtained according to

$$
C O P_{o p t}=0.5303 A_{r}^{0.4338}\left(\tilde{T}_{e}\right)^{18.825}\left(\tilde{T}_{c}\right)^{-18.519}
$$

The correlation is valid for the range of parameters considered in this study i.e. $6.44 \leq A r \leq 10.64$, $30 \leq T_{c} \leq 40{ }^{\circ} \mathrm{C}$, and $4 \leq T_{e} \leq 16^{\circ} \mathrm{C}$. The $\mathrm{R}^{2}$ value for the non-linear regression analysis was $94.63 \%$ with the 96 observations considered. The number of iterations were 19 with a convergence tolerance factor of $10^{-10}$ and a standard error (measure of the accuracy of the predictions) of estimate of 0.0383 .

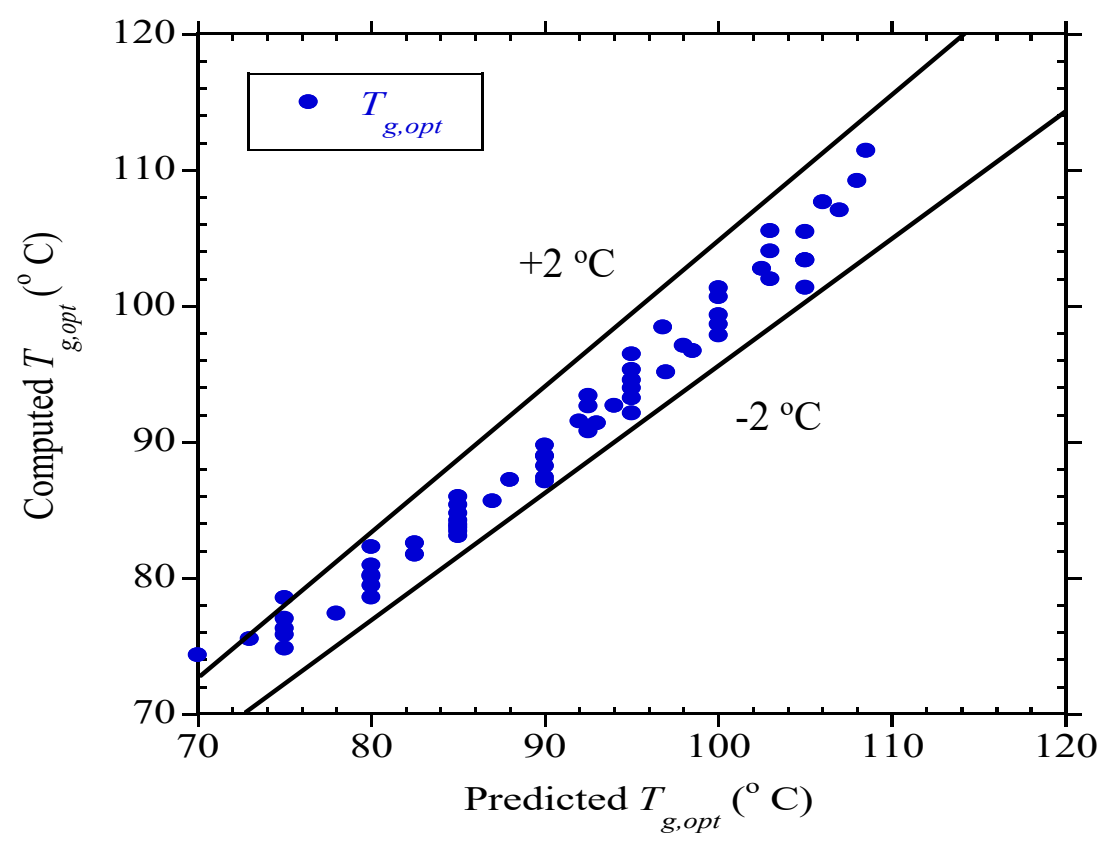

(a) 


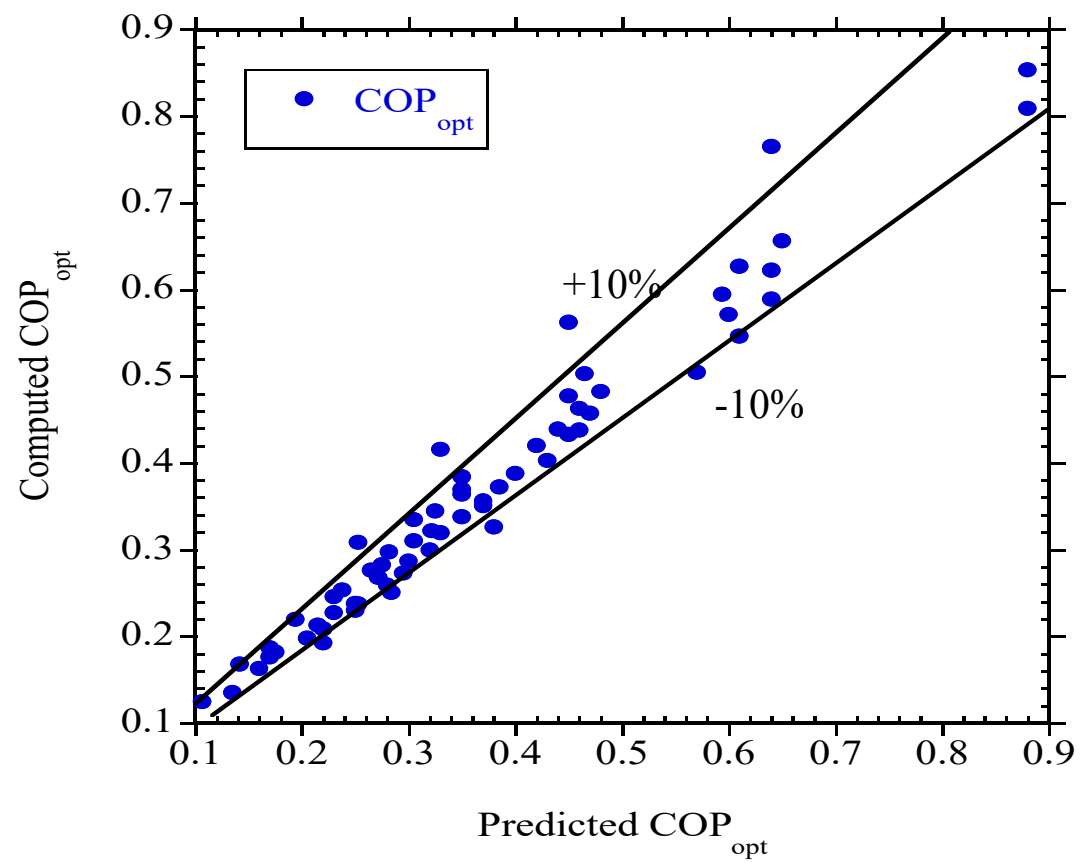

(b)

Fig. 12. Parity plots for (a) Optimal generator temperature and (b) Optimal COP

Figs. 12(a) and (b) show the parity plots for the optimal generator temperature and the optimal COP, respectively. As shown, the correlation in Eqns. (36) and (37) predict all the computed values of the optimal generator temperature within $\pm 2{ }^{\circ} \mathrm{C}$ and most of the values of the optimal COP within $\pm 10 \%$, respectively.

\subsection{Exergetic performance}

Based on the second law of thermodynamics, the exergy analysis method aids the determination of irreversibilities occurring in systems such that ways of minimizing these losses can be undertaken. Furthermore, it is easier to pinpoint where significant irreversibilities occur in the system, such that these components are isolated, and their performance improved rather than overhauling the entire system. Using the equations for exergy analysis presented in section 3.3, the exergy destruction rates in each component of the ejector refrigeration system have been determined. Fig. 13 (a) shows the exergy destruction rates in each component as a function of the generator temperature for an area ratio of 6.44 and an evaporator temperature of $8^{\circ} \mathrm{C}$. As depicted, the main contributor to the exergy destruction in the ejector system is the ejector itself due to the higher friction losses resulting from the expansion, entrainment and mixing processes. The other 
two components with significant losses are the generator and the condenser. In addition to the higher friction losses due to increased mass flow rate as the generator temperatures increase, the generator and condenser are at temperatures that are significantly higher than the dead state conditions.

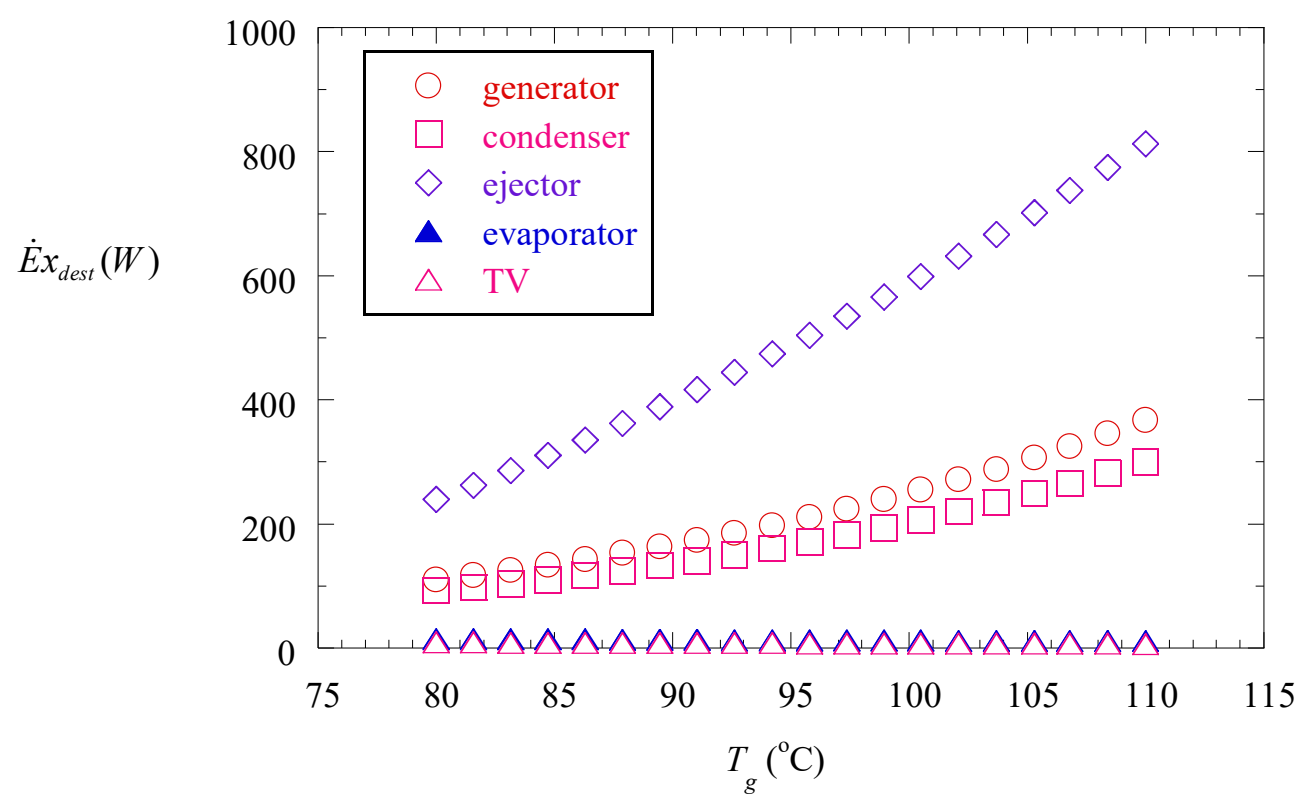

(a)

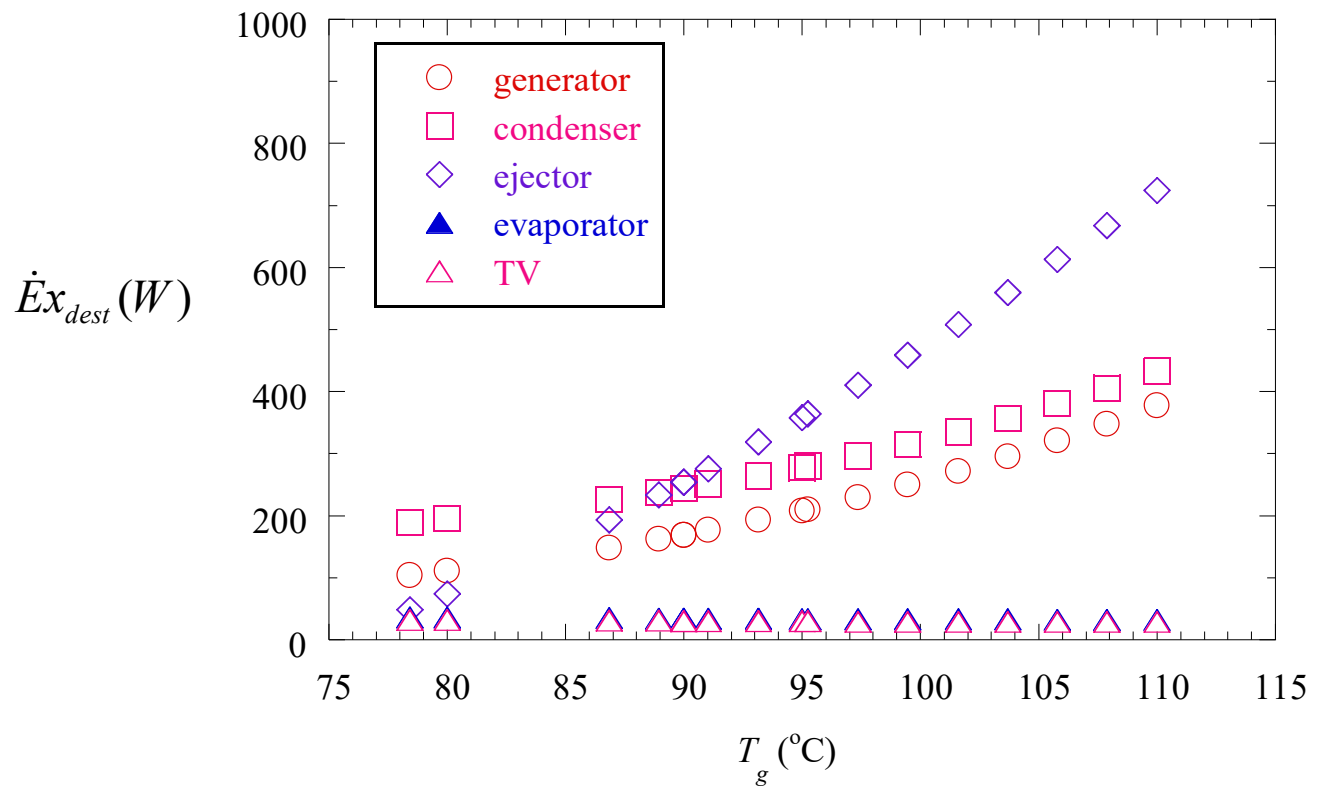

(b)

Fig. 13. Exergy destruction rate as a function generator temperature for components under the critical mode of operation with $T_{c}=35{ }^{\circ} \mathrm{C}$ and $T_{e}=8{ }^{\circ} \mathrm{C}$ for (a) $A_{r}=6.44$ and (b) $A_{r}=10.64$ 
As the area ratio increases, the irreversibilities in the ejector are not dominant at lower generator temperatures, especially at the highest area ratios as illustrated in Fig. 13 (b). With increased area ratios and lower generator temperatures (below $90^{\circ} \mathrm{C}$ ), the friction losses in the ejector are not as significant as the irreversibilities in the condenser and generator. Another observation at higher area ratios is that the condenser irreversibilities are now slightly greater than generator irreversibilities. This can be attributed to the fact that with increased area ratios, larger amounts of the secondary flow will be entrained in the ejector, subsequently giving rise to more losses in the condenser.

Overall, the exergy destruction rate from each component as well as the total exergy destruction rates increase as the generator temperature increases. Substantial increments in the irreversibility as the generator temperature rises are more pronounced in the ejector, condenser and the generator. The higher values of the total exergy destruction rate as the generator temperature increases is mainly due to the ejector irreversibility which have been shown to be the greatest contribution of system components.

The contribution of each component to the total irreversibility as a function of the generator temperature at area ratios of 6.44 and 9.41 is shown in Figs. 14(a) and (b), respectively. In these figures, the evaporator temperature, condensing temperature and the area ratio are $8{ }^{\circ} \mathrm{C}, 35^{\circ} \mathrm{C}$ and 6.44, respectively. Consistent with Fig. 13 and the accompanying discussion, the ejector has the largest contribution of about $51-56 \%$ for the range of generator temperatures considered. The exergy destruction rates at the same conditions in the generator, condenser, evaporator, and the throttle valve are between $23-24 \%, 18-20 \%, 0.5-3.5 \%, 0.5-2 \%$ and negligible for the pump. These values are somewhat consistent with a study by Alexis (2005) who performed an exergy analysis of an ejector system working with steam. In that study, the ejector had the greatest exergy loss, followed by the condenser, the generator, the evaporator, and the expansion device. The exergy losses in the ejector and condenser were 54\% and 27\%, respectively. Pridasawas and Lundqvist (2004) also showed that most exergetic losses occur in the ejector in their study of a solar driven ejector refrigeration system.

The total exergy destruction rates do not vary significantly as the evaporator temperature changes at a given area ratio and condensing temperature. The contribution of the evaporator to the total exergy destruction rate is very small. Given the significant losses in the ejector, condenser and 
generator, means of designing these components to be as efficient as possible should be studied. For the ejector, better manufacturing and machining processes could result in smooth ejectors with lower loss coefficients. The influence of ejector geometry on performance could also be studied to optimize performance.

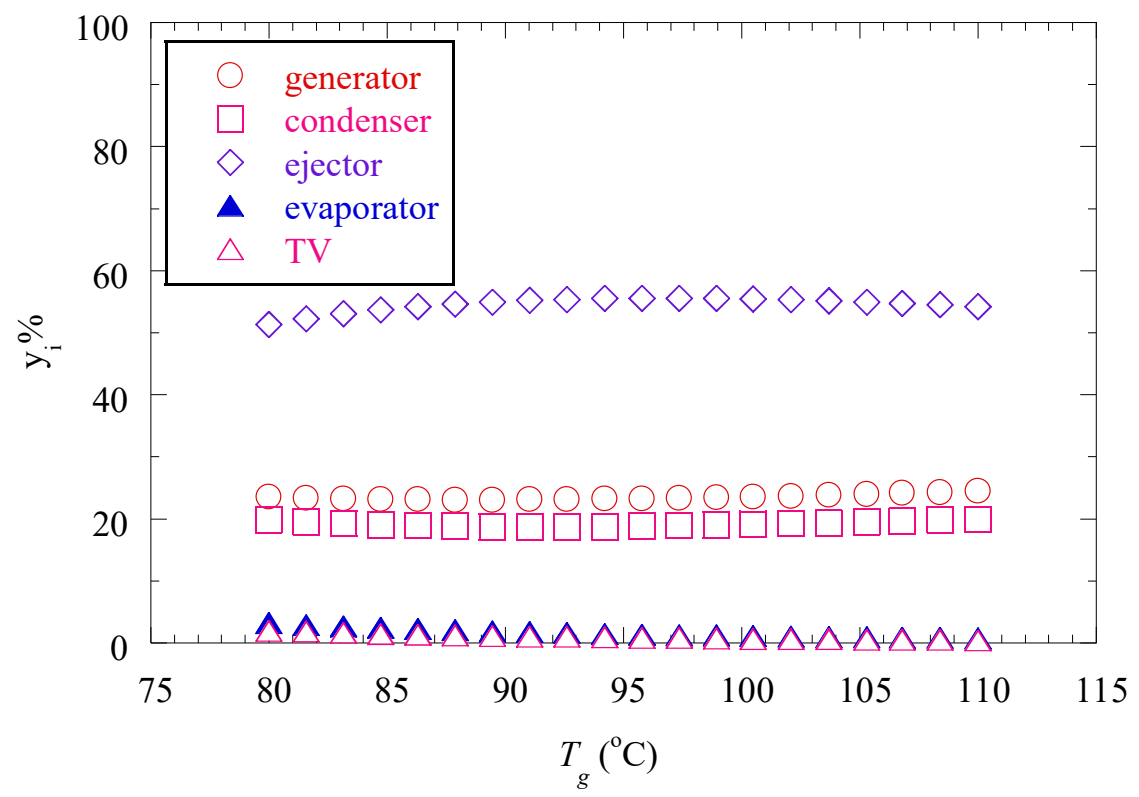

(a)

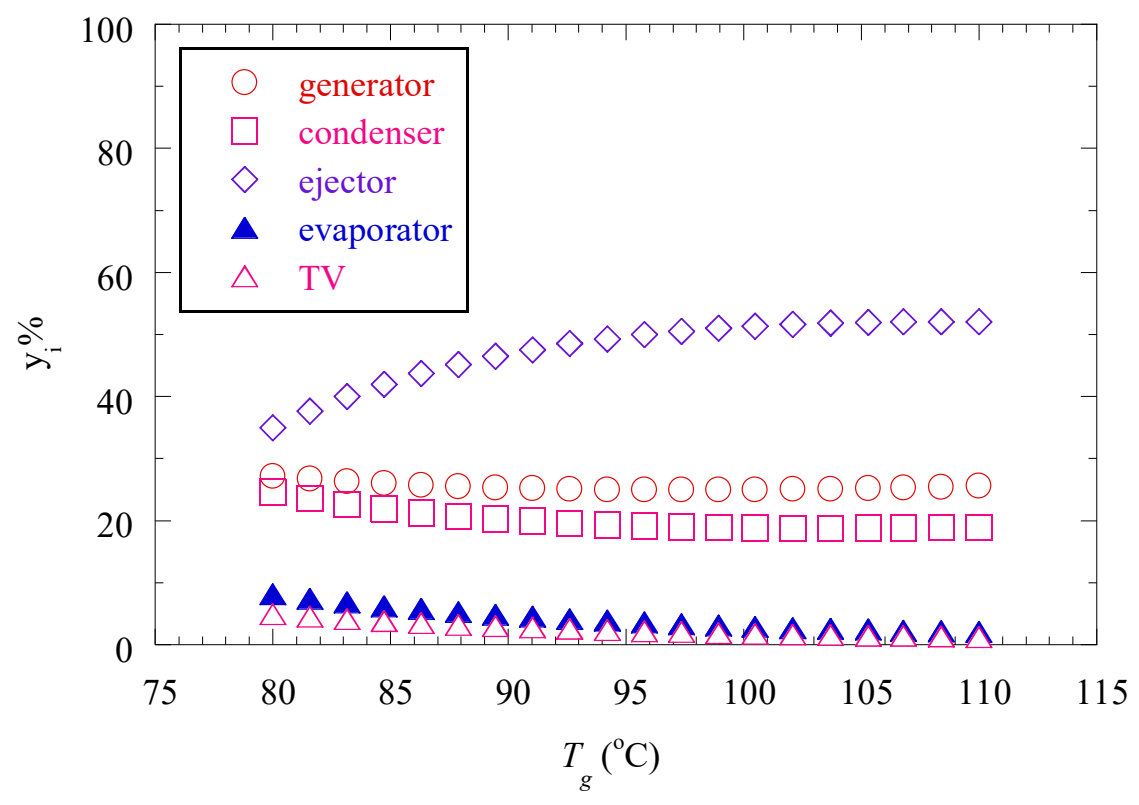

(b)

Fig. 14. Exergy destruction fraction for each component as a function as a function of generator temperature in the critical mode of operation at $T_{e}=8{ }^{\circ} \mathrm{C}$ and $T_{e}=35^{\circ} \mathrm{C}$ (a) $A_{r}=6.44$, and (b) $A_{r}=9.41$ 
There is no definite generator temperature that maximizes the exergetic performance. Moreover, there is no significant distinct change in the total exergy destruction rate as the area ratios change, only the contributions of the respective components vary. At the optimum working conditions presented in section 5.1, the exergy destruction rates and contributions of each component have been determined. The sample optimal operating conditions at each area ratio for condensing temperatures of $35^{\circ} \mathrm{C}$ at an evaporator temperature of $8{ }^{\circ} \mathrm{C}$ are shown in Tables 4 . As the table indicates, larger area ratios give higher COPs and cooling capacities but require higher generator temperatures.

Table 4. Optimal performance parameters for $T_{e}=8{ }^{\circ} \mathrm{C}$ and $T_{c}=35^{\circ} \mathrm{C}$

\begin{tabular}{lllllllllll}
\hline $\begin{array}{l}\text { Area } \\
\text { ratio } \\
(-)\end{array}$ & $\begin{array}{l}T_{g, \text { opt }} \\
\left({ }^{\circ} \mathrm{C}\right)\end{array}$ & $\begin{array}{l}C O P_{\text {opt }} \\
(-)\end{array}$ & $\begin{array}{l}\dot{Q}_{e, o p t} \\
(\mathrm{~W})\end{array}$ & $\begin{array}{l}T_{\mathrm{cc}} \\
\left({ }^{\circ} \mathrm{C}\right)\end{array}$ & $\begin{array}{l}y_{\mathrm{i}, \mathrm{ej}} \\
\%\end{array}$ & $\begin{array}{l}y_{\mathrm{i}, \mathrm{e}} \\
\%\end{array}$ & $\begin{array}{l}y_{\mathrm{i}, \mathrm{g}} \\
\%\end{array}$ & $\begin{array}{l}y_{\mathrm{i}, \mathrm{c}} \\
\%\end{array}$ & $\begin{array}{l}y_{\mathrm{i}, \mathrm{TV}} \\
\%\end{array}$ & $\begin{array}{l}\eta_{\mathrm{II}} \\
\%\end{array}$ \\
\hline 6.44 & 89.0 & 0.194 & 810 & 37.23 & 55.09 & 1.86 & 23.12 & 18.78 & 1.44 & 5.80 \\
7.04 & 90.0 & 0.230 & 1515 & 35.53 & 54.13 & 2.24 & 23.41 & 18.85 & 1.38 & 6.90 \\
7.51 & 91.5 & 0.246 & 2046 & 35.13 & 53.71 & 2.36 & 26.36 & 18.85 & 1.45 & 7.26 \\
7.73 & 92.5 & 0.251 & 1120 & 35.13 & 54.16 & 1.33 & 23.99 & 19.04 & 1.48 & 7.32 \\
8.28 & 96.0 & 0.254 & 1232 & 35.73 & 54.01 & 1.29 & 24.28 & 18.98 & 1.43 & 7.12 \\
8.62 & 97.5 & 0.259 & 1860 & 35.77 & 53.26 & 2.32 & 24.21 & 18.78 & 1.43 & 7.17 \\
9.13 & 99.6 & 0.265 & 1031 & 35.75 & 52.95 & 2.48 & 24.48 & 18.78 & 1.44 & 7.26 \\
9.41 & 100.0 & 0.279 & 1491 & 35.33 & 53.27 & 1.36 & 24.86 & 18.99 & 1.51 & 7.50 \\
10.64 & 105.0 & 0.296 & 2030 & 35.45 & 52.56 & 1.37 & 25.52 & 19.02 & 1.52 & 7.60 \\
\hline
\end{tabular}

The contribution to the total exergy loss is also shown for each component, indicating most losses to occur in the ejector at all area ratios. Tables at other combinations of the evaporator and condensing temperatures can be obtained showing similar trends. The exergetic efficiency for each area ratio is in most cases lower than $10 \%$. This is in line with the results obtained in earlier studies such as Pridasawas and Lundqvist (2004) in which the exergetic efficiency was much lower than $10 \%$. It was suggested that the exergetic efficiency is not a good indicator of the performance of cooling systems (Pridasawas and Lundqvist, 2004). This is possibly because in refrigeration systems the condensing and evaporating temperatures are close to the dead state conditions.

\subsection{Conclusion}


In this paper, a novel model has been used to determine the optimal energetic performance of an ejector refrigeration system working with R1233zd(E). Unlike most ejector models, the current model takes into account the pressure lift across the ejector and the area ratios. In addition, the thermodynamic analysis of the ejector system utilizing exergy analysis has been undertaken. Moreover, the performance in the critical and subcritical modes has been established and demonstrated. The performance of the ejector is shown to increase as the generator temperature reduces and as the area ratio increases, but this is at the expense of lower critical condensing temperatures and lower ejector breakdown temperatures. In the critical mode of operation, the $\mathrm{COP}$ reduces as the generator temperature increases and as the evaporator temperature and area ratios reduce.

Furthermore, the existence of an optimal generator temperature that maximizes performance at each area ratio and combination of condensing and evaporator temperatures has been confirmed. The optimal generator temperature increases with increasing area ratios and increasing condensing temperatures. The optimal COP rises with increasing evaporator temperatures, higher area ratios and reducing condensing temperatures. At $A_{r}=6.44$, the optimal COP is in the range 0.107 to 0.570 for condensing temperatures between $30^{\circ} \mathrm{C}$ and $40^{\circ} \mathrm{C}$ and evaporator temperatures between $4{ }^{\circ} \mathrm{C}$ and $16^{\circ} \mathrm{C}$. At the same condensing temperatures and evaporator temperatures, the optimal COP is in the range 0.135 and 0.610 for $A_{r}=7.73$, between 0.170 and 0.59 for $A_{r}=8.28$, between 0.202 and 0.594 for $A_{r}=9.41$ and between 0.22 and 0.61 with $A_{r}=10.64$. Higher values are observable at lower condensing temperatures and higher evaporator temperatures. For the first time, correlations for the optimal generator temperature and optimal COP at different operating conditions have been derived and presented, providing useful information for designers of these systems.

In general, most exergetic losses take place in the ejector, followed by the condenser, the generator, the evaporator, and the throttle valve, with the pump giving negligible exergy destruction rates. As an example, with an area ratio of 6.44 , an evaporator temperature of $8{ }^{\circ} \mathrm{C}$ and a condensing temperature of $35^{\circ} \mathrm{C}$, the exergy destruction rate in the ejector was about $51-56 \%$ and about 23 $-24 \%$ for the condenser, $18-20 \%$ for the generator, $0.5-3.5 \%$ for the evaporator, $0.5-2 \%$ for the throttle valve and negligible in case of the pump. To improve performance in the ejector, measures such as improving the smoothness of the ejector with quality machining processes could 
be implemented to ensure improved ejector efficiencies (reduced ejector losses) and thus better energetic and exergetic performance.

\subsection{Acknowledgements}

The authors acknowledge funding from the Canadian Research Chairs Program and the Natural Sciences and Engineering Research Council (NSERC).

\subsection{References}

A-Gas(R), 2018. Product information guide. Available at: https://www.agas.co.uk/media/3872/product-information-guide.pdf [last accessed: 11.09.2019].

Aidoun, Z., Ameur, K., Falsafioon, M., Badache, M., 2019. Current advances in ejector modeling, experimentation and applications for refrigeration and heat pumps. Part 2: TwoPhase Ejectors. Inventions 4, 16. doi:10.3390/inventions4010016

Alexis, G.K., 2005. Exergy analysis of ejector-refrigeration cycle using water as working fluid. Int. J. Energy Res. 29, 95-105. doi:10.1002/er.1042

Aphornratana, S., Chungpaibulpatana, S., Srikhirin, P., 2001. Experimental investigation of an ejector refrigerator: Effect of mixing chamber geometry on system performance. Int. J. Energy Res. 25, 397-411. doi:10.1002/er.689

Atmaca, A.U., Erek, A., Ekren, O., 2017. Investigation of new generation refrigerants under two different ejector mixing theories. $4^{\text {th }}$ Int. Conf. Energy Environ. Res. ICEER 2017. doi:https://doi.org/10.1016/j.egypro.2017.10.271

Besagni, G., Mereu, R., Inzoli, F., 2016. Ejector refrigeration: A comprehensive review. Renew. Sustain. Energy Rev. 53, 373-407.

Makhnatch, P., Khodabandeh, R., Palm. B., 2014. R1336mzz-Z - new generation nonflammable low GWP refrigerant. Department of Energy Technology, Royal Institute of Technology, https://www.kth.se/en/itm/inst/energiteknik/forskning/ett/projekt/koldmedier-med-laggwp/low-gwp-news/r1336mzz-z-ett-nytt-hogtemperaturkoldmedium-med-bra-egenskaper1.501202 [last accessed 21.08.2019].

Cardemil, J.M., Colle, S., 2012. A general model for evaluation of vapor ejectors performance for application in refrigeration. IREC 2011, Int. Renew. Energy Congr. doi:https://doiorg.ezproxy.lib.ryerson.ca/10.1016/j.enconman.2012.05.009

Chen, H., Zhu, J., Lu, W., 2018. Optimized selection of one- and two-stage ejectors under design and off-design conditions. Energy Convers. Manag. 173, 743-752. doi:10.1016/J.ENCONMAN.2018.06.113

Chen, J., Havtun, H., Palm, B., 2015. Conventional and advanced exergy analysis of an ejector refrigeration system. Appl. Energy 144, 139-151. doi:10.1016/j.apenergy.2015.01.139

Chen, J., Havtun, H., Palm, B., 2014. Screening of working fluids for the ejector refrigeration system. Int. J. Refrig. 47, 1-14. doi:10.1016/j.ijrefrig.2014.07.016 
Chen, W., Liu, M., Chong, D., Yan, J., Little, A.B., Bartosiewicz, Y., 2013. A 1D model to predict ejector performance at critical and sub-critical operational regimes. Int. J. Refrig. doi:https://doi.org/10.1016/j.ijrefrig.2013.04.009

Chen, W., Shi, C., Zhang, S., Chen, H., Chong, D., Yan, J., 2017. Theoretical analysis of ejector refrigeration system performance under overall modes. Appl. Energy. 185, 2074-2084. doi:10.1016/J.APENERGY.2016.01.103

Dai, Y., Wang, J., Gao, L., 2009. Exergy analysis, parametric analysis and optimization for a novel combined power and ejector refrigeration cycle. Appl. Therm. Eng. 29, 1983-1990. doi:10.1016/J.APPLTHERMALENG.2008.09.016

Dennis, M., Cochrane, T., Marina, A., 2015. A prescription for primary nozzle diameters ifor solar driven ejectors. Sol. Energy. doi:https://doi.org/10.1016/j.solener.2015.02.045

Eames, I.W., Aphornratana, S., Haider, H., 1995. A theoretical and experimental study of a small-scale steam jet refrigerator. Int. J. Refrig. doi:https://doi.org/10.1016/01407007(95)98160-M

Edberg, O., Waddelove, A., Gibson, G., 2012. Space heating and cooling, IEA energy technology system analysis program, Technology Brief. IEA ETSAP, 2012; R02:1-10.

García del Valle, J., Saíz Jabardo, J.M., Castro Ruiz, F., San José Alonso, J.F., 2014. An experimental investigation of a R-134a ejector refrigeration system. Int. J. Refrig. doi:https://doi.org/10.1016/j.ijrefrig.2014.05.028

Linde, 2019. Refrigerants environmental data - ozone depletion and global warming potential. https://www.linde-gas.com/en/images/Refrigerants\%20environmental\%20GWPs tcm 17 111483.pdf [last accessed:10.09.2019]

Honeywell, 2015. Solstice®ze Refrigerant (HFO-1234ze) - the environmental alternative to traditional refrigerants. 1-8. https://www.honeywell-refrigerants.com/europe/wpcontent/uploads/2014/10/Solstice-ze-brochure-Fourth-Generation-LR-140925.pdf. [last accessed:12.09.2019]

EES, 2019. Engineering Equations Solver. http://www.fchart.com/ees/

Huang, B.J., Chang, J.M., 1999. Empirical correlation for ejector design. Int. J. Refrig. doi:https://doi.org/10.1016/S0140-7007(99)00002-X

Huang, B.J., Chang, J.M., Wang, C.P., Petrenko, V.A., 1999. A 1-D analysis of ejector performance. Int. J. Refrig. doi:https://doi.org/10.1016/S0140-7007(99)00004-3

IEA, 2019, "Energy Efficiency: Buildings. The global exchange for energy efficiency policies, data and analysis" Available at: https://www.iea.org/topics/energyefficiency/buildings/ [last accessed:14.02.2019].

Keenan Henry, J., Neumann, E.P., Lustwerk, F., 1950. An investigation of ejector design by analysis and experiment. J. Appl. Mech. Trans. ASME 17, 299-309.

Kopchick, S., Scancarello, M., 2017. New refrigerants designation and safety classifications, in: E360 Forum. Chicago, IL, pp. 1-28.

Li, F., Chang, Z., Tian, Q., Wu, C., Wang, X., 2017a. Performance predictions of dry and wet vapors ejectors over entire operational range. Energies. doi:10.3390/en10071012

Li, F., Tian, Q., Wu, C., Wang, X., Lee, J.-M., 2017b. Ejector performance prediction at critical 
and subcritical operational modes. Appl. Therm. Eng. doi:https://doi.org/10.1016/j.applthermaleng.2016.12.116

Martel, J., Parakh, D., 2015. Capturing the value of thermal energy-innovations in ejector technology from CanmetENERGY, Natural Resources Canada.

Mohammadi, A., 2019. An investigation of geometrical factors of multi-stage steam ejectors for air suction. Energy 186, 115808. doi:10.1016/J.ENERGY.2019.07.138

Mwesigye, A., Dworkin, S.B., 2018. Performance analysis and optimization of an ejector refrigeration system using alternative working fluids under critical and subcritical operation modes. Energy Convers. Manag. 176, 209-226. doi:10.1016/j.enconman.2018.09.021

Ozone Secretariat, 2019. Handbook for the Montreal Protocol on Substances that Deplete the Ozone Layer. Nairobi, Kenya: UNEP; 2006. p. 1-743.

Parveen Banu, J., Mani, A., 2019. Numerical studies on ejector with swirl generator. Int. J. Therm. Sci. 137, 589-600. doi:10.1016/J.IJTHERMALSCI.2018.11.033

Pridasawas, W., Lundqvist, P., 2004. An exergy analysis of a solar-driven ejector refrigeration system. Sol. Energy. doi:https://doi.org/10.1016/j.solener.2003.11.004

Solstice ${ }^{\circledR}$ ze Refrigerant (HFO-1234ze). https://www.honeywellrefrigerants.com/europe/product/solstice-1234ze/ [last accessed: 10.08.2019]

Regulation (EU) No. 517/2014 of the European Parliament and of the Council of 16 April 2014 on Fluorinated Greenhouse Gases and Repealing Regulation (EC) No. 842/2006. Official Journal of the European Union 2014; L150:195-230.

Saleh, B., 2016. Performance analysis and working fluid selection for ejector refrigeration cycle. Appl. Therm. Eng. 107, 114-124. doi:10.1016/j.applthermaleng.2016.06.147

Shestopalov, K.O., Huang, B.J., Petrenko, V.O., Volovyk, O.S., 2015. Investigation of an experimental ejector refrigeration machine operating with refrigerant R245fa at design and off-design working conditions. Part 1. Theoretical analysis. Int. J. Refrig. 55, 201-211. doi:https://doi.org/10.1016/j.jirefrig.2015.01.016

Śmierciew, K., Gagan, J., Butrymowicz, D., Łukaszuk, M., Kubiczek, H., 2017. Experimental investigation of the first prototype ejector refrigeration system with HFO-1234ze(E), Applied Thermal Engineering. Elsevier Ltd. doi:https://doi.org/10.1016/j.applthermaleng.2016.08.140

Tashtoush, B., Algharbawi, A.B.R., 2019. Parametric study of a novel hybrid solar variable geometry ejector cooling with organic Rankine cycles. Energy Convers. Manag. 198, 111910. doi:10.1016/j.enconman.2019.111910

Tashtoush, B., Alshare, A., Al-Rifai, S., 2015. Performance study of ejector cooling cycle at critical mode under superheated primary flow. Energy Convers. Manag. doi:https://doi.org/10.1016/j.enconman.2015.01.039

Thongtip, T., Aphornratana, S., 2017. An experimental analysis of the impact of primary nozzle geometries on the ejector performance used in R141b ejector refrigerator. Appl. Therm. Eng. doi:https://doi.org/10.1016/j.applthermaleng.2016.08.100

Ullah, K.R.R., Saidur, R., Ping, H.W.W., Akikur, R.K.K., Shuvo, N.H.H., 2013. A review of solar thermal refrigeration and cooling methods, Renewable and Sustainable Energy 
Reviews. Pergamon. doi:https://doi.org/10.1016/j.rser.2013.03.024

UNEP Ozone action branch, 2009. HCFCs controlled under the Montreal Protocol. http://web2.unep.fr/hcfc/about/default.aspx?type=list [last accessed: 28.08.2018].

Untea, G.A., Dobrovicescu, A., Grosu, L., Mladin, E.C., 2013. Energy and exergy analysis of an ejector refrigeration system. UPB Sci. Bull. Ser. D Mech. Eng. 75, 111-126.

Wang, C., Wang, L., Wang, X., Zhao, H., 2017. Design and numerical investigation of an adaptive nozzle exit position ejector in multi-effect distillation desalination system. Energy 140, 673-681. doi:10.1016/J.ENERGY.2017.08.104

Wang, J.H., Wu, J.H.H., Hu, S.S.S., Huang, B.J.J., 2009. Performance of ejector cooling system with thermal pumping effect using R141b and R365mfc, Applied Thermal Engineering. Pergamon. doi:10.1016/j.applthermaleng.2008.08.015

Yang, X., Long, X., Yao, X., 2012. Numerical investigation on the mixing process in a steam ejector with different nozzle structures. Int. J. Therm. Sci. 56, 95-106. doi:10.1016/J.IJTHERMALSCI.2012.01.021

Zegenhagen, M.T., Ziegler, F., 2015. A one-dimensional model of a jet-ejector in critical double choking operation with R134a as a refrigerant including real gas effects. Int. J. Refrig. doi:https://doi.org/10.1016/j.jirefrig.2015.03.013

Zhang, K., Zhu, X., Ren, X., Qiu, Q., Shen, S., 2017. Numerical investigation on the effect of nozzle position for design of high performance ejector. Appl. Therm. Eng. doi:10.1016/j.applthermaleng.2017.07.085

Ziapour, B.M., Abbasy, A., 2010. First and second laws analysis of the heat pipe/ejector refrigeration cycle. Energy 35, 3307-3314. doi:10.1016/J.ENERGY.2010.04.016 